\title{
Cipango
}

Cipango Cahiers d'études japonaises

\section{Les mineurs coréens dans la littérature de langue japonaise : entre silence contraint et risque de banalisation}

Korean Miners in Japanese Literature: Between Constrained Silence and the Risk of Trivialization

\section{Mayumi Shimosakai}

\section{(2) OpenEdition \\ Journals}

\section{Édition électronique}

URL : https://journals.openedition.org/cipango/3601

DOI : 10.4000/cipango.3601

ISSN : 2260-7706

\section{Éditeur}

INALCO

\section{Édition imprimée}

Date de publication : 1 juillet 2020

ISBN : 9782858313426

ISSN : 1164-5857

\section{Référence électronique}

Mayumi Shimosakai, « Les mineurs coréens dans la littérature de langue japonaise : entre silence contraint et risque de banalisation », Cipango [En ligne], 23 | 2020, mis en ligne le 16 juin 2020, consulté le 30 juin 2021. URL : http://journals.openedition.org/cipango/3601 ; DOI : https://doi.org/ 10.4000/cipango.3601

\section{(2) $(1) \Theta$}

Cipango est mis à disposition selon les termes de la Licence Creative Commons Attribution - Pas d'Utilisation Commerciale 4.0 International. 


\title{
Les mineurs coréens dans la littérature de langue japonaise : entre silence contraint et risque de banalisation
}

\author{
Korean Miners in Japanese Literature: Between \\ Constrained Silence and the Risk of Trivialization
}

Mayumi ShimosaKai

Maître de conférences, université d'Orléans

Exhalez vos parfums, fleurs de prunier sur la colline où on extrait le charbon.

\section{香に匂へうに掘る岡の梅の花 ${ }^{1}$}

Si ce hokku de Matsuo Bashō, composé en 1688, permet de situer les débuts balbutiants de la littérature japonaise de la mine à l'époque où apparurent les premiers enregistrements documentaires sur les houillères de Chikuhō et de $M_{i i k e}^{2}$, il faudra néanmoins attendre les années 1920 et l'épanouissement de la
1. KATŌ, 1998, p. 17.
2. IKEDA, 2012, p. 67. 


\section{CIPANGO}

126 Cahiers d'études japonaises $\mathrm{n}^{\circ} 23$

littérature prolétarienne pour que les écrivains accordent une place majeure à l'univers minier - et plus longtemps encore, pour que cet univers soit associé à l'émigration forcée des travailleurs coréens.

Ueno Eishin 上野英信 (1923-1987), lui-même mineur, écrivain et contributeur de la revue des mineurs de Chikuhō, Sākuru mura サークル 村 ${ }^{3}$, relève pourtant l'importance de la présence des Coréens au sein des mines japonaises dans un récit de 1958 alimenté par son vécu, Les Histoires drôles du fond de la terre, où il donne en exemple plusieurs mots coréens passés dans le jargon des mineurs :

Ketsuwari porte l'idée de « fuite », d' « évasion », on l'utilise d'ailleurs dans l'expression verbale ketsu o waru (« casser le cul »). Un mineur ketsuwari est donc un mineur évadé. On écrit souvent ce mot avec les sinogrammes 尻割り, qui n'est qu'une graphie imputable à sa prononciation, tout comme baketsu (seau) s'écrirait 馬穴. Il est évident que ce mot est en réalité une altération du coréen kecchogari, signifiant lui-même « évasion ». Les mots d'origine coréenne sont nombreux dans le langage de la vie quotidienne des mineurs : les contremaîtres sont appelés yanban ; pour dire «mange! », on dit panmogura. Et pour cause : nombre d'immigrés coréens ont afflué vers les mines dès l’ère Meiji.

ケツワリとは逃亡・脱走の意であり、動詞としてはケ ツをワルというふうに用いられている。ケツワリ坑夫と いえば脱走坑夫のことになる。よく尻割りという漢字が 宛てられるけれど、これはバケツを馬穴と書くのとおな じく、まったくの宛字にすぎない。もともと脱走を意味 する朝鮮語の「ケッチョガリ」の転訛であることは明ら かだ。係員のことをヤンバンといったり、飯をくえとい うところをパンモグラといったり、炭鉱で日常用語と化

3. Sākuru mura サークル村 (Le Cercle-village), vol. 1 (1.1-2.6, septembre 1958juin 1959), vol. 2 (2.7-3.5, juillet 1959-mai 1960) et vol. 3 (3.6-4.6, septembre 1960octobre 1961), Tōkyō, Fuji shuppan 不二出版, 2013 [2006]. 


\section{した朝鮮語がすこぶる多いが、これはすでに明治時代か らかなり多くの朝鮮人移民が炭鉱に流れこんできている ためである4。}

Ces propos sont cependant exagérés. D’après une étude du ministère de l'Intérieur ${ }^{5}$, le nombre de Coréens dans les départements où l'activité minière était importante demeure relativement peu élevé en 1910, soit deux ans avant la fin de l'ère Meiji : 26 individus à Hokkaidō, 163 à Yamaguchi, 335 à Fukuoka et 173 à Nagasaki. Néanmoins, l'intérêt de ce passage réside non pas dans son exactitude historique, mais dans son témoignage de la trace indélébile laissée par les mineurs coréens dans l'histoire des houillères au Japon.

Les travailleurs coréens commencent à arriver plus nombreux à partir de l'ère Taishō (1912-1926), lorsque les entreprises minières recrutent pour la première fois expressément des Coréens ${ }^{6}$, qu'elles vont même chercher dans leur pays. Reflétant ce changement, la population coréenne de ces départements a sensiblement augmenté en 1920: 1719 individus à Hokkaidō, 1640 à Yamaguchi, 6798 à Fukuoka, et 2242 à Nagasaki. La présence au Japon des travailleurs coréens et leurs conditions de travail, plus dégradées que celles de leurs collègues japonais, étaient déjà mentionnées en 1929 par Kobayashi Takiji 小林多喜二 (1903-1933) dans Le Bateau-usine :

Le matin, ils étaient tous traînés vers le chantier avant le lever du soleil. Et ils devaient s'atteler au travail jusqu'à ce qu'ils ne voient plus que l'éclat pâle de leurs pioches dans la pénombre qui dissimulait leurs propres pieds. Ils enviaient même les forçats qui travaillaient dans la prison des environs. Le pire sort était réservé aux Coréens qui étaient foulés aux pieds par les contremaîtres, les chefs d'équipe et même par leurs congénères japonais ${ }^{7}$.
4. Ueno, 1971 [1967], p. 108.
5. Tonomura, 2004, p. 44.
6. Takeuchi, 2013, p. 18, 40, 49, 81, 181, $259 \& 292$.
7. Ковауashi, 2009, p. 56-57. 
Cette œuvre emblématique de la littérature prolétarienne précède en effet d'une dizaine d'années leur arrivée massive en raison de la seconde guerre sinojaponaise (1937-1945), ainsi que la promulgation des réquisitions envoyant les Coréens dans les mines de charbon japonaises. La mobilisation des Japonais et l'augmentation de la demande en matériaux militaires provoquent durant ce conflit un manque de main-d'œuvre qui sera un facteur majeur de l'explosion des chiffres de l'immigration coréenne. C'est ainsi qu'est promulguée en 1939 la «Clause sur l'immigration des travailleurs coréens » (Chōsenjin rōdōsha naichi ijūnikansuru ken 朝鮮人労働者内地移住に関する件), favorisant l'emploi de ces derniers dans les domaines d'activité liés à la production militaire (mines de charbon, chantiers de construction et industrie de l'armement, etc. $)^{8}$. Les mines de charbon étaient plus particulièrement privilégiées : 62,7\% des Coréens travaillant au Japon ouvraient dans le secteur minier ${ }^{9}$. Ce changement de situation est également décelable dans les statistiques de résidence des Coréens en 1940 : ils étaient à présent 38273 à Hokkaidō, 72700 à Yamaguchi, 116864 à Fukuoka et 18144 à Nagasaki. Cette hausse se poursuit jusqu'en 1945: 96206 individus à Hokkaidō, 144302 à Yamaguchi, 205402 à Fukuoka et 61773 à Nagasaki.

La nette augmentation de la population coréenne dans les zones minières résultait d'une méthode d'embauche des travailleurs coréens pour le moins musclée. Les entreprises minières autorisées à « recruter » des travailleurs en Corée déléguaient cette embauche aux policiers, voire aux fonctionnaires du gouvernement général de Corée (Chōsen sōtokufu 朝鮮総督府). Cette politique s'est accentuée avec l'enlisement de la guerre, le manque de main-d'œuvre se faisant de plus en plus sensible. Entre 1941 et 1943, les paysans coréens pauvres et sans protection sont obligés de partir au Japon sous la pression des puissances locales, qui les contraignent parfois à remplacer leurs fils réquisitionnés ${ }^{10}$. Faute de travailleurs, ce système de recrutement s'écroule vers 1944, et l'enlèvement pur et simple se généralise ${ }^{11}$. En septembre de la même année, le recrutement des
8. TONOMURA, 2004, p. 37-38.
9. YAMADA et al., 2005, p. 79.
10. Ibid., p. 96.
11. Ibid., p. 101. 
Coréens s'effectue désormais sous forme de réquisition, dont le refus expose à une amende maximale de mille yens, voire une peine carcérale pouvant atteindre douze mois de réclusion. Le système de réquisition ne permet cependant guère de remédier au manque de main-d'œuvre, tant les cas de fuite sont fréquents ${ }^{12}$.

Outre leur émigration forcée au Japon, ces travailleurs sont de surcroît confrontés à une forte discrimination. Ils travaillent souvent à l'intérieur de la mine, où les tâches sont plus dangereuses qu'en extérieur : dans une grande compagnie de Hokkaidō, les travailleurs coréens ont pu représenter jusqu’à 84,6\% des mineurs de fond sur certains sites. Par ailleurs, les statistiques montrent que ceux-ci furent confrontés à un volume de travail bien plus élevé que leurs homologues japonais. Bien que la pratique du travail forcé soit aussi courante chez les mineurs japonais que chez les mineurs coréens, ces derniers subissaient néanmoins, et à la différence de leurs collègues japonais, de violentes punitions physiques. Lorsqu'ils s'absentaient en raison d'une maladie ou d'une blessure, ils perdaient de fait leur droit à la nourriture ${ }^{13}$.

La reconnaissance de l'《émigration forcée »(kyōsei renkō 強制連行) des Coréens fait l'objet d'une polémique parmi les historiens : certains émettent en effet des doutes sur le caractère contraint de leur recrutement ${ }^{14}$. Or, les témoignages ne manquent pas, et il est certain que ces travailleurs ont servi, comme le montre l'ouvrage de Yamada Shōji, Koshō Tadashi et Higuchi Yūichi, dans des mines dont la réputation de dangerosité n'échappait à personne ${ }^{15}$. Le nombre important d'évasions au cours du voyage ou une fois arrivés à la mine démontre le caractère

12. Ibid., p. 103-104.

13. Ibid., p. 184-189.

14. Ibid, p. 23. L'historien notoirement révisionniste Fujioka Nobukatsu 藤岡信勝 (1943) emploie de manière volontaire le terme de 《réquisition» (chōyō 徵用) à la place d' « émigration forcée » (kyōsei renkō 強制連行). Si la réquisition concernait aussi bien les Japonais que les Coréens, ces derniers étaient selon lui « Japonais à l'époque coloniale ».

15. Voir leur chapitre : « Le processus de mobilisation de la main-d'œuvre coréenne durant la guerre 》(Chōsenjin senji rōdōin no katei 朝鮮人戦時労働動員の課程), ibid., p. $67-121$. 


\section{CIPANGO \\ 130 Cahiers d'études japonaises $n^{\circ} 23$}

forcé de leur déplacement et de leur travail. Pour Ueno Eishin, le monde des houillères ne peut être abordé au Japon sans évoquer les travailleurs coréens.

L'univers de la mine fait son apparition assez précocement dans la littérature japonaise, par le biais de la littérature prolétarienne. C'est l'ouvrage Les Préparatifs de mariage de Hashimoto Eikichi 橋本英吉 (1898-1978), publié en $1927^{16}$, qui marque à proprement parler le début de la littérature minière par des écrivains eux-mêmes mineurs ${ }^{17}$. La mine est alors un thème récurrent, abordé sous différents angles par les écrivains, et cette situation perdurera pendant la guerre. Aucun sujet $n$ 'y manque : luttes ouvrières ${ }^{18}$, glorification du charbon comme élément fondamental des guerres dans la logique expansionniste du Japon de l'époque ${ }^{19}$, etc. Si la quasi-totalité de la littérature prolétarienne a été écrasée par la censure dans les années 1930, une partie a néanmoins été « recyclée », si l'on puit dire, dans la littérature de propagande. C'est notamment le cas de cette littérature minière, où les mineurs étaient exaltés comme des héros. Au sortir de la guerre, ce thème se retrouve de fait moins visible, mais certains des écrivains héritiers du mouvement prolétarien, qui avaient été mis à l'écart par la censure à partir des années 1930, créent la revue La nouvelle littérature japonaise (Shin-Nihon bungaku 新日本文学) en $1945^{20}$, offrant un nouveau lieu de publication à la littérature des houillères. Plus tard, la dégradation des villes minières, consécutive

16. Налнimoto, 1927, 1930 [1927] \& 1988 [1927], p. 713.

17. IKEDA, 2012, p. 58.

18. En témoignent entre autres le roman de НаSнimoto Eikichi Cercueil et drapeau rouge (1946 [1928]) et la pièce de théâtre de Mryoshi Jūrō, La Poussière de charbon, 1931.

19. Ikeda Hiroshi montre ainsi comment l'importance du charbon dans le contexte de la guerre a irrémédiablement entraîné Hashimoto Eikichi vers une écriture adhérant à la politique expansionniste du Japon, suite à l'Incident de Manchourie, en 1931. Son roman Les Galeries de la mine en est un exemple flagrant (Наsнimoto, 1939). Ikeda, 2012, p. 22-24.

20. Cette revue a été éditée de 1945 à 2004 par la « Société littéraire du nouveau Japon » (Shin-Nihon bungaku-kai 新日本文学会), initialement créée par des écrivains de la littérature prolétarienne en quête de nouvelles formes de littérature. 
à la fin des houillères japonaises dans la période d'après-guerre ${ }^{21}$, se substituera au thème de la mine.

La littérature minière suit ainsi l'histoire du Japon du $\mathrm{Xx}^{\mathrm{e}}$ siècle, et sans doute conviendrait-il de se demander pourquoi il a fallu attendre près de vingt ans pour que les travailleurs coréens s'y trouvent représentés à la hauteur de leur présence réelle. La présente étude tâchera par conséquent de retracer, de la période coloniale aux œuvres les plus récentes, le parcours de ces mineurs coréens dans la littérature japonaise et la littérature en langue japonaise issue de l'immigration coréenne. Quelques précisions s'imposent cependant, en raison des difficultés rencontrées dans l'élaboration du corpus présidant à ce travail. Sauf erreur de notre part, et dans une lecture la plus large possible ${ }^{22}$ de la littérature zainichi 在日 ${ }^{23}$, seuls deux écrivains coréens d'expression japonaise traitent des houillères dans leur œuvre : Yi Hoesŏng (1935-) et Kim Hakyŏng (1938-1985). Ce faible nombre pourra sembler paradoxal, puisque ces auteurs coréens de langue japonaise font partie intégrante de la population concernée par cette page de l'histoire, mais nous verrons en quoi leur démarche est à tous points de vue singulière.

Notre étude se penchera dans un second temps sur le cas des écrivains japonais. Dans la littérature du charbon, relativement abondante, la présence des mineurs coréens est parfois évoquée, sans pour autant constituer un sujet important. Nous avons à cet égard sélectionné les rares romans et nouvelles accordant un rôle conséquent à des personnages coréens. Parmi ces ouvrages, ceux de Yuzurihara Masako 譲原昌子 (1911-1949) et de Īo Kenshi 飯尾憲士 (1926-2004) présentent un point commun : l'utilisation du témoignage-fiction. Puis, nous nous arrêterons plus longuement sur Inoue Mitsuharu 井上光晴 (1925-1992), unique écrivain chez qui la mine, dans toute sa dimension historique,

21. Citons dans cette perspective le roman d'InOUe, Le pays natal affamé, 1961. Repris dans InOue, 1974 [1965].

22. Entrerait alors dans ce cadre la nouvelle de Honjō Mutsuo, « Les petits frères excessifs » (1987).

23. Zainichi signifie résidant au Japon. Lorsque ce terme est employé sans précision de nationalité, et en raison du nombre important de Coréens sur le sol japonais, il désigne généralement une personne coréenne. 


\section{CIPANGO}

132 Cahiers d'études japonaises $n^{\circ} 23$

constitue avec les mineurs coréens un thème de prédilection. Nous verrons enfin, avec deux écrivains nés après la Seconde Guerre mondiale, Shimada Sōji 島田荘 司 (1948) et Hahakigi Hōsei 帚木蓬生 (1947), comment la littérature minière engagée et militante, qui dénonçait jusqu'ici la violence des rapports coloniaux, a débouché au tournant des années 1990 sur un nouveau genre, celui du roman policier.

\section{Une mémoire indicible}

L'omniprésence des travailleurs coréens dans les mines de charbon pourrait laisser supposer que de nombreux écrivains coréens de langue japonaise ont écrit sur ce thème. Or, le sujet reste clairement mineur dans la littérature zainichi : contrairement à ce que nous pourrions attendre, peu d'écrivains coréens ont abordé ce sujet au Japon. Deux raisons peuvent être évoquées d'emblée : en premier lieu, la trajectoire de la population ayant travaillé dans les mines de charbon, qui est souvent repartie en Corée après la Seconde Guerre mondiale. Si les mineurs coréens furent massivement recrutés, voire emmenés de force au Japon à partir de 1939, les travaux de Tonomura Masaru démontrent que la majorité des travailleurs arrivés entre cette date et 1945 sont ensuite retournés en Corée, car ils avaient initialement émigré seuls, en laissant leur famille au pays ${ }^{24}$. Selon lui, la majorité des Coréens ayant continué à résider au Japon aurait rejoint le territoire japonais en dehors du système de mobilisation générale des travailleurs nécessité par le conflit. Étant donné qu'il fallut attendre la deuxième génération d'immigrés pour que les écrivains d'origine coréenne se mettent à écrire en japonais, la probabilité était assez faible de voir apparaître des travailleurs-écrivains parmi la population minière, du fait même de son retour en Corée. La genèse de la littérature zainichi se situe de surcroît dans les années 1960, bien après le retour des mineurs coréens dans leur pays ; à cette époque, les Coréens du Japon ont de tout autres sujets de préoccupation, comme la division de la Corée, ou la question de leur identité. Outre ce contexte historique peu favorable à l'avènement d'une

24. Tonomura, 2004, p. 377. 
littérature du charbon au sein de la production littéraire zainichi, le sujet semble également poser un autre type de problème.

Yi Hoesŏng (1935) est l'un des rares écrivains coréens à faire apparaître dans ses œuvres les mines de charbon, quoiqu'elles n'y occupent jamais une place prépondérante. Yi fait partie de la première génération d'écrivains coréens au Japon ; il est né à Karafuto, actuelle Sakhaline, où les travailleurs coréens du charbon étaient déjà présents lorsque l'île était encore japonaise - et où son univers littéraire demeure résolument ancré. Ainsi, la mère du protagoniste de La Femme qui bat le linge 25 , publié en 1971 et couronné par le prix Akutagawa l'année suivante, a travaillé à la mine. Cette œuvre demeure néanmoins un portrait maternel dressé par le personnage de son fils; le métier exercé par cette dernière avant sa naissance n'est par conséquent jamais réellement abordé. Le seul passage évoquant la houillère figure dans la lettre adressée par la jeune femme à ses parents ${ }^{26}$. Elle a en effet rencontré à la mine son futur mari, celui qui deviendra le père du protagoniste. Les parents du personnage principal sont donc d'anciens mineurs, bien que cet épisode ne dévoile rien concernant le travail minier de ce jeune couple. S'il n'est dessiné qu'en creux, ce lieu de rencontre est cependant symbolique : il est le point de départ, le lieu où s'est bâtie la charpente de cette famille, du reste ébranlée par la mésentente du couple et la mort de la mère.

La Femme qui bat le linge n'est cependant pas le seul roman de Yi Hoesŏng à évoquer les mines de charbon. Pour Kayako ${ }^{27}$, publié en 1970, s'inscrivait déjà dans une houillère, même si à l'instar de La Femme qui bat le linge, la mine est loin d'être le thème central de l'œuvre. Le sujet principal de ce roman est avant tout l'amour - et la rupture - entre Im Sangjun, étudiant à Tōkyō, et Kayako, la fille adoptive d'un ami de son père. Parallèlement à cette histoire d'amour, le roman dépeint un conflit entre un père et ses enfants au-delà de la différence intergénérationnelle. L'épisode relatant la rencontre entre le père et la mère est sensiblement identique à celui de La Femme qui bat le linge : après avoir débuté sa carrière de mineur à Jōban, le père du protagoniste a travaillé sur plusieurs sites

25. YI, $1971 \& 2006$ [1971].

26. Ibid., p. 254-255.

27. YI, $1970 \& 2006$ [1970]. 


\section{CIPANGO}

134 Cahiers d'études japonaises $n^{\circ} 23$

et s'est marié lors de ses pérégrinations ${ }^{28}$. Cette fois-ci, la rencontre est rapportée par le père : en racontant son périple, ce dernier reproche à son fils l'ingratitude de ses enfants envers lui. Cet épisode, qui remonte au début de son séjour au Japon, n'a pas pour objectif d'illustrer directement le travail à la mine, mais de marquer le contraste entre le père et le fils (le père a en effet toujours exercé des métiers physiques, tandis que le fils est étudiant). La mine sert ainsi de toile de fond à un conflit bien plus profond qu'un simple écart entre générations : par ce biais, ce sont à la fois les différences sociales et historiques qui sont évoquées. Ayant souffert d'avoir vécu dans le Japon colonialiste, le père considère que ses enfants mènent une vie facile. Ici encore, la mine est non seulement présente, mais même essentielle - et pourtant jamais décrite par le père, comme si le sujet était frappé de tabou. On peut donc légitimement se demander si ce roman, sous-tendu par un sujet impossible à évoquer par ses protagonistes, ne serait pas une illustration du silence assourdissant des auteurs zainichi sur la mine.

Dans son roman La Lampe à alcool, publié en $1973^{29}$, un autre écrivain coréen de langue japonaise de la même génération, Kim Hakyŏng (1938-1985), parle toutefois beaucoup plus explicitement de l'impossibilité, voire du refus d'évoquer la mine. Le protagoniste de ce roman, Shunkichi, est le plus jeune des trois enfants d'Insun. Collégien, il rêve d'avoir son propre laboratoire de chimie. Il réussit à obtenir une place dans le débarras et à acheter le matériel nécessaire pour son activité de petit scientifique. Cependant, sa famille se déchire : son frère aîné, étudiant à Tōkyō et fierté de la famille, ne s'entend plus avec son père, fervent admirateur de Kim Il-sung, et s'apprête à voyager en Corée du Sud. Dans le contexte de la division des deux Corées transplantée au sein de la famille, le père et le fils s'affrontent. Outre ce violent conflit, le roman évoque également l'opposition entre le père et sa fille. La sœur ainée de Shunkichi fréquente en effet un homme japonais avec qui elle envisage le mariage, un projet inadmissible pour le père. Cette famille est à l'image de l'histoire de la Corée - colonisée puis divisée. La mésentente entre le père et les enfants est par ailleurs représentative des dissensions entre deux générations : l'une a connu la période coloniale,

28. Ibid., p. 135.

29. Kim, $1973 \& 2006$ [1973]. 
l'autre, née au Japon, a vécu dans la richesse matérielle. Le roman se conclut sur la métaphore d'un échec cuisant : ne pouvant réussir à fédérer cette famille en pleine déliquescence, Shunkichi détruit tout son matériel de chimiste si durement acquis.

Ainsi, l'intrigue de ce roman concentre tous les problèmes des familles zainichi. La figure d'Insun est typique de la situation de la littérature des Coréens au Japon : le père, qui dirige sa colère contre sa femme et qui la bat, se retrouve isolé des autres membres de la famille. Les enfants, ne partageant pas ses valeurs, ne peuvent que le renier. La violence du père vis-à-vis de sa famille paraît excessive et incompréhensible, mais le roman fait clairement le lien avec son expérience passée :

Quand son histoire avançait trop et en arrivait à la période qui avait suivi son départ forcé au Japon, le visage du père aussitôt se refermait, comme s'il revenait subitement à lui-même. Son regard, figé de façon inquiétante, s'enflammait de colère à vue d'œil.

À son arrivée au Japon, Insun avait travaillé dans une mine à Hokkaidō pour s'en évader moins d'un an plus tard, avant d'errer un certain temps dans la région du Tōhoku, travaillant deci delà sur des chantiers. Shunkichi aurait voulu savoir ce qu'il s'était alors passé, d'autant que des choses comme l'émigration forcée ou l'évasion dépassaient largement son imagination, mais Insun était curieusement peu bavard lorsqu'il s'agissait d'évoquer cette période de sa vie. Tout comme les déserteurs de l'armée étaient lourdement blâmés de leur évasion, les Coréens emmenés de force au Japon devaient subir d'abominables punitions s'ils venaient à se faire rattraper dans leur fuite. Insun avait donc été incroyablement déterminé pour fuir la mine. Pourtant, Shunkichi avait beau le prier de lui conter cette évasion, il ne lui opposait qu'un vague sourire mêlé d'amertume, sans jamais faire l'effort d'entrer dans les détails.

\footnotetext{
だが、話が進みすぎ、父が強制連行によって日本に渡 ってきてからのことになると、父はにわかにわれに返っ
} 


\section{CIPANGO}

たように顔が引き締まり、目つきはまた不気味に据わっ てきて、みるみる怒りに然えてくる。

日本に来てからは、仁舜は、北海道の炭鉱で働いて いたのだが、一年たらずでそこを脱走し、しばらく東北 のあちこちを土方をしながら転々としていた。強制連行 にしろ、脱走にしろ、それらは俊吉の想像を絶すること で、それだけに俊吉はいっそうそのときのことを知りた いと思うのだが、仁舜はなぜか、当時のことにかぎって 多くを語ろうとしない。脱走した兵士が過酷な刑を受け たように、脱走した被強制連行朝鮮人も、見つかれば酷 い刑を受けたはずだ。だから、仁舜は、おそらく決死の 覚悟で炭鉱を逃げたに違いないのだが、俊吉が脱走のと きの模様をいくらたずねても、仁舜は歪みのこもつた曖 昧な微笑を浮かべるだけで、詳しく語ろうとしない30。

Ce qui distingue ce père des autres membres de la famille ne peut se résumer à une différence de générations. Ce personnage est profondément marqué par l'humiliation qu'il a subie dans sa jeunesse : la contrainte de venir au Japon pour travailler comme un quasi-esclave dans une mine de charbon. Le ressentiment provoqué par cette expérience demeure au plus profond de son être : c'est l'expérience d'un colonisé. Le travail dans la houillère, conséquence de la colonisation, apparaît dans ce roman comme l'élément destructeur d'une famille coréenne au Japon. Or, comme l'illustre très bien le passage précédent, l'horreur de l'expérience est sur le point d'être dite, mais demeure informulée. Le roman s'arrête en quelque sorte à la lisière du dicible. L'histoire de ce père violent dépasserait-elle tant « l'imagination » qu'elle ne pourrait non seulement être communiquée au personnage du fils, mais racontée au lecteur ? L'histoire estelle trop douloureuse pour être dite, ou est-ce la fiction elle-même qui se montre incapable d'assumer ce rôle?

Le silence d'Insun vient donc finalement rejoindre celui des personnages de La Femme qui bat le linge et de Pour Kayako. Aussi bien dans les œuvres de

30. Ibid., p. 179-180. 
Yi Hoesŏng que dans le roman de Kim Hakyŏng, la mine de charbon apparaît comme un sujet sur lequel les personnages se taisent. Shunkichi est bien conscient que l'intérêt du récit de son père dépasse largement le vécu individuel, que son travail forcé et son évasion sont en rapport avec un événement historique : le colonialisme. Maurice Halbwachs définit la « mémoire collective » comme un ensemble d'événements vécus au sein d'un même groupe, et la distingue en cela de l'histoire écrite par les historiens, qui serait, elle, une succession d'événements ${ }^{31}$. La mémoire relative au travail dans la mine est donc collective, puisqu'elle concerne une page historique de la période coloniale demeurée ancrée dans la communauté coréenne établie au Japon. Ici réside le paradoxe de ces deux écrivains, qui du fait de leur origine, seraient pourtant en mesure de transmettre cette mémoire collective demeurant ineffable : seule est rapportée l'impossibilité de dire. Afin que cette mémoire soit dévoilée plus explicitement, il faut quitter le domaine de la littérature zainichi et entrer dans celui de la littérature japonaise.

\section{La littérature-témoignage}

Emmanuel Bouju évoque, à propos des Émigrants de Winfried Georg Sebald ${ }^{32}$, « un processus d'attestation de l'histoire vers un modèle de reproduction textuelle de voix-témoins », en l'absence de preuve documentaire. L'ouvrage de Sebald représente pour lui un exemple typique de ce phénomène ${ }^{33}$. Fiction évoquant la communauté juive déracinée après le génocide, Les Émigrants contient en effet de nombreuses photos dont le rapport avec ce qui est raconté ne tient pas toujours de l'évidence. L'ouvrage entretient ainsi l'ambiguïté, se situant volontairement entre fiction et faits véridiques. On retrouve de la part des écrivains engagés - japonais, cette fois - une même volonté de rapporter la violence qu'ont subi les travailleurs coréens des houillères par le biais du témoignage-fiction, à l'œuvre dans deux nouvelles typiques du procédé : «La raclée coréenne » de Yuzurihara Masako, et « Le Rapport de Ch'oe Ǔlsun » d'İo Kenshi.

31. HalbWaChs, 2005 [1950], p. 97-142.

32. SeBALd, 2001.

33. Bouju, 2006, p. 48. 
La présence des mineurs coréens n'a pas échappé à Yuzurihara Masako, qui jusqu'en 1941, fut institutrice à Karafuto. Sa nouvelle « La raclée coréenne ${ }^{34}$ », publiée en 1949 dans la revue La nouvelle littérature japonaise, est racontée par une narratrice-protagoniste elle-même institutrice dans une école primaire de Karafuto. L'intrigue se base sur les relations entre cette dernière et l'un de ses élèves, remarquable d'intelligence. Le père de ce garçon coréen est mineur, et sa sœur aînée, chargée de trier le charbon dans la même mine. En rendant visite à cette famille, la narratrice s'aperçoit que cet élève joyeux et populaire cache un autre visage : il affiche en effet une inexplicable froideur devant cette soudaine visite de sa maîtresse. Tout est mis au jour lorsque cette famille disparait, ainsi que le médecin de la ville. L'institutrice découvre que ce médecin, le docteur Iwasa, est non seulement le frère aîné de son élève, donc un Coréen, mais l'important dirigeant d'un mouvement indépendantiste. La disparition de la famille fait suite à son arrestation. La narratrice comprend alors que si le garçon a été embarrassé par sa visite, c'était en raison d'une réunion secrète organisée au même moment dans la maison.

Dans cette nouvelle, la mine sert de révélateur à la violence qui pèse constamment sur les Coréens de Karafuto. La narratrice consacre deux pages à la narration d'un épisode lié à la 《 raclée coréenne (chōsen-yaki 朝鮮ヤキ), punition physique qui selon elle, fut pratiquée dans les houillères de Karafuto jusqu’à la fin de la Seconde Guerre mondiale :

Dans le Karafuto colonial, le contremaître des mines détenait un pouvoir absolu, y compris celui de police ; les travailleurs le regardaient avec effroi. Depuis la Guerre sino-japonaise, Karafuto se débattait face à la concurrence minière pour déterrer tout le charbon de l'île, c'est-à-dire vider la terre entière de ses richesses. Aussi le manque de main d'œuvre était-il aussi sensible que le « débauchage » fréquent, tout comme la fuite des mineurs, que le contremaître surveillait avec vigilance. Le débauchage visait plus particulièrement la main-d'œuvre coréenne, qui travaillait dur pour

34. YUZURIHARA, $1949 \& 2012$ [1949]. 
le salaire le plus bas qui fût. De la mine $\mathrm{A}$ à la mine $\mathrm{B}$, de la mine $\mathrm{B}$ à la mine $\mathrm{C}$, on revendait les travailleurs tout en engraissant les intermédiaires. On tentait de débaucher des hommes au péril de sa propre vie, mais une fois le pot-aux-roses découvert, c'étaient aussi bien les intermédiaires que les travailleurs en cavale qui subissaient la « raclée coréenne », les laissant à demi morts.

植民地樺太の炭鉱の労務係りと言えば、ヤマの警察 権を握る絶対権力で、労働者からは戦慄の目をもって眺 められる存在であった。支那事変以来、樺太も島中の石 炭を掘り出す競争、いわば地球の財産を空っぽにする競 争で大童であったから、労働力の払底は甚だしかった。 そこで労働者の（玉抜き）や逃亡が激しく、労務係りの 看視もきびしかった。玉抜きは殊に、最低の賃金で、よ く働く朝鮮人労働者を衫らって行われた。炭鉱のAからB へ、BからCへと斡旋屋の懷中を肥やしながら労働者は売 買される。玉抜きには命がけで潜入してくるが、バレて 捕まったが最後、斡旋やも逃亡未遂の労働者も、朝鮮ヤ キで半殺しにされる35。

Selon la rumeur qui circule, l'un des Coréens débauchés se trouverait dans un état grave suite à cette fameuse « raclée coréenne », ce qui n'est pas sans provoquer la colère des mineurs coréens et les pousser à organiser une grève. Ce mouvement est cependant brisé par l'arrivée des policiers armés et des arrestations massives qui s'ensuivent : selon la narratrice, leur rébellion courageuse fut matée « par le système de fer au moyen duquel règne l'empereur ${ }^{36}$. » La nouvelle révèle non seulement quelle punition radicale est infligée aux mineurs coréens, mais insiste également sur l'exaspération de ces derniers, qui les mènera à ce soulèvement réprimé par les autorités japonaises. Mais le châtiment ne se borne pas à l'univers de la mine et de la répression des grèves. Quand « la raclée coréenne » se

35. Ibid., p. 548.

36. Ibid., p. 549. 
140 Cahiers d'études japonaises n²3

transforme en moyen de torture pour extorquer un aveu, c'est le pouvoir de la mine et celui de la police qui se confondent. Aussi l'un des rares complices du médecin, ne supportant plus cette correction que la police, à son tour, lui inflige, se résout-il à dénoncer la chose. La violence de cette punition pratiquée dans les mines de Karafuto prend ici une portée plus générale, car elle rejoint la violence institutionnelle que subissent tous les Coréens au Japon.

« La raclée coréenne », écrit immédiatement après la Seconde Guerre mondiale, dépeint le Karafuto du temps du conflit. Vingt-cinq ans après la parution de cette nouvelle, İo Kenshi publie en 1974 « Le Rapport de Ch'oe Ŭlsun ${ }^{37}$ », où il utilise le même dispositif du témoignage-fiction, en l'occurrence celui d'une Coréenne clandestine dans le Japon de l'après-guerre. Bien qu'il ne soit pas considéré comme un écrivain zainichi par les chercheurs, Io est étroitement lié à la communauté coréenne du Japon par son ascendance coréenne côté paternel, qu'il n'a découverte qu'à l'adolescence, alors qu'il tentait d'intégrer l'école navale ${ }^{38}$. « Le Rapport de Ch'oe Ǔlsun » se compose en grande partie du récit que livre aux juges une femme au foyer coréenne arrêtée en raison de sa clandestinité, puis internée au Centre d'immigration d'Ōmura et menacée d'expulsion du territoire japonais. Dans sa plaidoirie, elle raconte sa vie et celle de son mari. La nouvelle est constituée de deux récits alternés : celui de Ch'oe Ǔlsun elle-même, et celui de son avocat, Shimizu Daisaku. Clairement l'auteur de cette œuvre désire décrire les conditions de vie des Coréens résidant au Japon. Cette nouvelle se veut pédagogique pour les lecteurs ignorant l'histoire de cette population.

Le récit de Ch'oe Ǔlsun met en scène ses péripéties et celles de son mari. Cette femme née au Japon, puis partie en Corée du Sud avec sa grand-mère qui souhaitait retourner dans son pays natal après l'indépendance, dut cependant revenir clandestinement sur le territoire japonais à l'âge de seize ans pour vivre avec ses parents, ayant perdu sa grand-mère et l'oncle chez qui elle était logée. Le

37. İo, $1974 \& 2006$ [1974].

38. L'écrivain raconte les circonstances de la découverte de la nationalité de son père dans son récit autobiographique Umi no mukō no chi. Īo, 2001 [1980]. 
récit du parcours de son mari retrace pour sa part le destin des Coréens emmenés de force au Japon pendant la Seconde Guerre mondiale :

Mon mari a été forcé de débarquer dans un port de Toyama du nom de Fushiki, ou quelque chose comme ça, avec près de mille autres Coréens. Là, on l'a fait monter dans un train et emmené à la mine de Hitachi. Comme il était l'aîné de sa fratrie, et que sa mère était morte de maladie, il s'inquiétait pour son père qu'il avait laissé précipitamment en Corée, sans pouvoir rien y faire. [...] On les a fait travailler durement dans des fosses. Certains tombaient malades à cause de la malnutrition, car la nourriture y était de mauvaise qualité ; certains succombaient d'avoir trop travaillé ; d'autres, encore, mouraient sous les chutes de rochers. Quant à ceux qui contestaient le chef, ils étaient roués de coups jusqu'à en perdre connaissance. Quelques agents de la police militaire étaient toujours là, et il semblerait que bien des mineurs alités par la maladie furent tirés du lit sous les coups et les reproches de ne pas se montrer dignes $\mathrm{du}$ « peuple de l'empire ».

夫は、富山県伏木港とかいうところに、千名ちかく の同胞といっしょに上りくさせられ、そこから汽車にの せられて、日立こう山につれてこられました。夫は長男 で、お母さんは病死していましたので、自分がとつぜん いなくなったあとのお父さんのことが心ぱいでしたが、 どうすることもできませんでした。 $(\cdots . .$.$) たべるもの$ はわるく、栄ようがなくなって、びょう気になるひと、

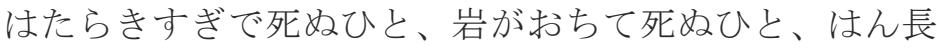
さんにはんたいするひとは、たいへんなぐられて、気を うしなうほどシゴキとかいうものをされました。「憲 兵」さんが何人かいつもいて、びょう気でねていると、 「皇国民」としてはずかしくないかとひきおこされ、な ぐられたひともおおかったそうです39。

39. Ibid., p. 355-356. 
Ainsi, le récit sur le travail minier qu' Insun refusait de livrer à son fils dans $L a$ Lampe à alcool est finalement dévoilé par Ch'oe Ǔlsun. Le discours de cet écrivain, qui se démarque notoirement de l'univers zainichi en raison de son parcours, acquiert de fait une force nouvelle, et peut enfin faire la lumière sur l'indicible. Le passage cité résume bien l'itinéraire des Coréens emmenés de force au Japon, entre enlèvement et conditions de travail proches de l'esclavage. Le lieu de travail du mari de Ch'oe Ǔlsun n'est pas choisi au hasard, car cette réalité historique demeure incontestablement l'une des pages les plus sombres de la période coloniale du Japon.

Si le récit de cette Coréenne clandestine nous éclaire sur la violence jadis subie par les Coréens, celui de l'avocat se montre instructif quant à leur situation au moment de l'écriture : l'arrière-plan historique se complique avec la division de la Corée, non sans répercussions sur le changement de statut des Coréens au Japon ou le problème de leur nationalité. La stratégie de l'avocat pour faire annuler l'obligation de quitter le territoire pesant sur sa cliente consiste à rappeler aux juges les contraintes migratoires exercées par le Japon sur le père de cette dernière, qui justifient selon lui que les Coréens résidant au Japon ne soient pas traités de la même façon que les autres étrangers.

L'intérêt de cette nouvelle réside justement dans ce rappel de l'histoire coloniale dont Ch'oe Ǔlsun et son mari sont les victimes. Le tribunal étant par excellence le lieu où la vérité doit être révélée, le contexte juridique présidant au récit revêt une portée indéniablement symbolique. La mise en scène choisie par İo, certainement motivée par le désir de mettre au jour les crimes du colonialisme, est bien entendu destinée à souligner le caractère véridique du récit de Ch'oe Ülsun. En tant que condensé des crimes du Japon colonial, le motif des mines de charbon se révèle donc un choix stratégique de la part de l'écrivain. Les exactions telles que le déplacement et le travail forcés des Coréens doivent pour lui non seulement être dévoilées, mais également jugées : afin que les relations entre les deux pays puissent s'apaiser, c'est toute l'histoire coloniale du Japon qui devrait à ses yeux faire l'objet d'un procès. 


\section{Inoue Mitsuharu : un cas exemplaire d'écrivain engagé}

Inoue Mitsuharu occupe une position singulière dans la littérature du charbon : il a en effet consacré plusieurs de ses romans à ce sujet. Ayant lui-même travaillé dans la mine souterraine de Sakido en 1941, à l'âge de quinze ans ${ }^{40}$, il décrit principalement les houillères et les mineurs durant la Seconde Guerre mondiale, lorsque ces sites fonctionnaient à plein régime, et dépasse parfois ce cadre temporel pour évoquer la dévastation d'après-guerre des anciennes villes minières. Sa biographie mentionne également son arrestation et sa détention par la police, qui l'aurait à l'époque soupçonné d'avoir incité un collègue coréen à se joindre à un mouvement d'ordre indépendantiste. Cet épisode est éloquent, car contrairement à la majorité de la littérature du charbon, qui ne s'épanche pas sur le cas des mineurs coréens, Inoue accorde une place importante à leur présence dans les houillères. La littérature minière, dont l'origine remonte pourtant à la littérature prolétarienne, a en quelque sorte été « enrôlée » dans l'idéologie expansionniste du Japon impérial pendant toute la guerre d'Asie-Pacifique ${ }^{41}$. Si la littérature de la mine a quasiment disparu après la guerre, sans doute à cause de cette association à la littérature de propagande, Inoue reste l'un des rares écrivains à avoir continué d'écrire sur les houillères.

\section{Une volonté de description réaliste des travailleurs coréens dans l'univers minier}

Comme nous l'avons constaté, la mine demeure un sujet ineffable chez Yi Hoesŏng et Kim Hakyŏng. Les nouvelles de Yuzurihara Masako et d'Īo Kenshi dévoilent certes la violence de cet univers, mais leurs témoins, toutefois, ne sont pas des mineurs. Inoue Mitsuharu se distingue sur ce plan des écrivains précités : non

40. C'est du moins ce que révèle son autobiographie. Ce fait est cependant démenti par sa propre fille, également écrivaine, selon qui Inoue n'aurait jamais travaillé dans la mine. Cette fictionalisation de ses propres mémoires ne fait cependant que témoigner de l'importance du sujet pour l'écrivain. Inoue, 1972 [1968], p. 249 ; Inoue, 2013 [2008], emp. 435-444.

41. Citons par exemple le roman de Наsнiмото Eikichi, Les galeries de la mine, 1939. 


\section{CIPANGO}

144 Cahiers d'études japonaises $n^{\circ} 23$

seulement ses protagonistes sont eux-mêmes des travailleurs miniers, mais il fait de ce monde souterrain le sujet principal de textes où les mineurs coréens occupent assurément une place importante. L'une des premières œuvres d'Inoue abordant cette question, « L'île de Nagagutsu ${ }^{42}$ », publiée dans La nouvelle littérature japonaise en 1956, mentionne déjà les conditions de travail particulièrement difficiles de ces derniers. Le protagoniste de ce roman, Rimoto Sanchin (ou Li Sanchin, selon qu'on l'appelle à la japonaise ou à la coréenne), est toujours assigné par le contremaître qui l'a pris en haine à une taille particulièrement pénible, imbibée d'eau, où il lui est impossible de se mettre debout. À plusieurs reprises, le mineur coréen demande à changer de chantier d'abatage et à travailler comme ses collègues, en roulement entre les tailles, mais sa demande n'est jamais acceptée. S'il doit travailler dans une taille difficile, c'est bien parce qu'il est coréen :

«Sugi... fit calmement Numasaki. Est-il bien normal de se tuer comme ça à la tâche ? Tu sais très bien de quoi je parle, toi qui travailles à l'entrée de la fosse. Pourquoi crois-tu qu' il y ait autant de travailleurs exténués qui abandonnent leur poste en plein travail ? Les pires tailles, elles sont quasiment toutes attribuées aux Coréens. Et encore, Li Sanchin a eu de la chance! C'est comme si on mettait les Coréens à la place des piliers pourris... parce que les Coréens, eux, ne se plaignent pas. »

「杉君」沼崎はおさえた。「手がまわらないという口 実で、死んでしまっていいのかね。君は繰込だからよく わかっているだろうが、毎日毎日、くたくたになって、 中途昇坑者が何人もでるのは何の為だと思う。しかも悪 い〈払い〉はほとんど全部が朝鮮人だ。李三鎮の場合は よっぽど運がよかったのだ。まるで腐れた坑木の代わり

42. Nous pouvons supposer que le modèle de cette île minière est certainement Sakido, la plus grande mine de Nagasaki, où l'auteur a vécu au début des années 1940, d'autant que son récit se déroule en 1943. InOUE, 1956 \& 1979 [1965]. 
に朝鮮人を枠にでも入れるように……朝鮮人は文句を言 わないからね初。」

En plus d'être envoyés dans les tailles dangereuses, les Coréens sont également confrontés à la violence physique de leurs supérieurs. L'épisode suivant, qui décrit le traitement d'un travailleur coréen remonté du fond de la mine durant son service en raison de douleurs abdominales, illustre cette violence injustifiée :

« Monsieur, j'ai mal au ventre, mal au ventre... »

Chō jeta un œil vers Sugi.

« Le contremaître de la fosse ne m'a pas donné le certificat, alors que je l'ai demandé plusieurs fois...

- Quoi ! Tu as osé monter sans certificat ? Bon, d'accord. Assieds-toi là. Tu étais dans la taille Ouest $n^{\circ} 2$, c'est ça ?

- Oui, Monsieur. J'ai mal au ventre. Je ne peux pas travailler dans la taille Ouest $n^{\circ} 2 \ldots$

- Entendu. Reste assis là. Je vais faire partir ton mal de ventre. » $[\ldots]$

L'homme chargé de l'examen physique arracha à Chō sa chemise. Soudain, il frappa son dos nu avec une ceinture de caoutchouc dont il s'était emparé sans que l'on ne s'en aperçoive. Un gémissement semblable au sifflement de flûte s'échappa de la bouche de Chō.

「ヤンバン、腹痛い、腹痛い.......」

張は杉の方をちらとみた。

「証明書は、坑内ヤンバンくれなかった、いくらたの んでも…..

「なにい、証明書を持たずに上ってきたのか、よし、 そこに坐れっ、お前は〈西二片払〉だったな」

「ええ、ヤンバン、腹痛い。〈西二片払〉ではとて も…..」

43. Ibid., p. 163. 
146 Cahiers d'études japonaises $n^{\circ} 23$

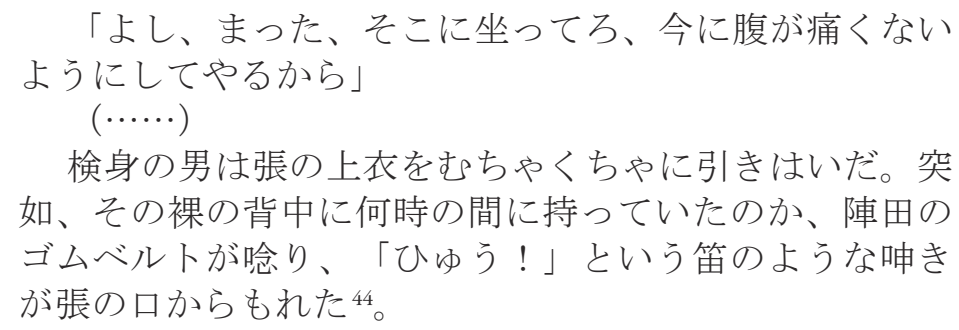

検身の男は張の上衣をむちゃくちゃに引きはいだ。突 如、その裸の背中に何時の間に持っていたのか、陣田の ゴムベルトが唸り、「ひゅう！」という笛のような呻き が張の口からもれた乱。

Si la catégorie des travailleurs des mines de charbon est alors considérée comme l'extrême inférieur de l'échelle sociale japonaise, les mineurs coréens pourraient bien se situer encore plus bas que les mineurs japonais. À l'instar des nouvelles de Yuzurihara Masako et d'Īo Kenshi, la mine d'Inoue révèle les exactions qu'Insun de La Lampe à alcool n'avait pas voulu raconter à son fils. L'île minière imaginaire de cet écrivain s'avère ainsi un concentré des terreurs engendrées par le Japon impérial, au mépris de la dignité humaine des Coréens.

\section{La place des femmes et la dénonciation des rapports de type colonial}

Dans sa volonté de se positionner au plus proche des individus les plus fragiles de la société japonaise, que ce soient les minorités discriminées (burakumin 部落 民) ou les victimes de la bombe atomique (bibakusha 被爆者), Inoue Mitsuharu ne manque pas d'évoquer la présence des femmes coréennes dans les mines. En s'intéressant à leur situation, c'est une nouvelle brèche qu'il ouvre dans l'univers littéraire souvent masculin des mines de charbon. Une brèche qu'il était bien normal pour lui d'ouvrir, étant donné son engagement.

Dans « L'île de Nagagutsu », la mine est un lieu où règnent des rapports de type colonial. S'ils dépassent de manière générale la binarité des sexes, ces rapports de domination revêtent néanmoins un caractère particulier lorsque ce sont les femmes qui en font l'objet. Ainsi, quand la fille de Li Sanchin tente à son tour d'intervenir auprès du contremaître après l'échec du plaidoyer de Sugi Akio pour que son père change de taille, le contremaître profite de l'occasion pour abuser

44. Ibid., p. 166-167. 
d'elle. Tandis que les droits élémentaires du père à bénéficier du même traitement que les autres mineurs coréens sont bafoués, sa fille subit un viol. La violence exercée sur les hommes coréens par la discrimination et la punition physique pèse différemment sur les femmes coréennes : s'y ajoute la dimension de l'humiliation sexuelle.

Le roman d'Inoue mentionne en outre la présence de prostituées coréennes sur l'île. À travers le personnage de Yo Rishun, prostituée et petite amie de Numasaki, un travailleur japonais de la mine, c'est une autre figure de la femme coréenne que l'écrivain représente. Numasaki, qui a jadis étudié à l'université de Keijō ${ }^{45}$, se sent proche des Coréens, et plus particulièrement de Rishun, qui lui rappelle un ancien amour. Le passé de la jeune femme n'est certes qu'effleuré, et le roman fournit peu d'informations sur ces prostituées. Ce personnage est cependant efficace du point de vue de la stratégie auctoriale, car il souligne à nouveau le rapport de double domination qui ronge la mine. La présence de prostituées autour de la mine de Sakido est un fait historique attesté : Takeuchi Yasuto mentionne dans son ouvrage l'existence de deux lupanars coréens sur l'île ${ }^{46}$. Le gouvernement japonais ne s'est donc pas contenté d'importer de force la main-d'œuvre; il a également obligé des Coréennes à se prostituer, leur faisant ainsi subir une double domination, à la fois coloniale et masculine.

Si Inoue Mitsuharu dénonce pleinement cette domination en couvrant toutes les formes qu'elle a pu historiquement arborer, il complexifie son analyse par la mise en scène d'un personnage en position de bourreau. Unan Chikao, l'un des protagonistes de La Foule sur la terre ${ }^{47}$, publié en 1963, est un médecin exerçant dans une ville du département de Nagasaki où burakumin et hibakusha se côtoient. Le sujet principal de ce roman est d'ailleurs l'affrontement entre ces deux populations discriminées pour différentes raisons : le viol d'une jeune fille burakumin par un hibakusha provoquera entre ces deux communautés une flambée de haine, qui trouvera son paroxysme dans la mort de la mère de la victime. Si la mine de charbon existe seulement dans les souvenirs qu'Unan Chikao a gardé de

45. Keijō était le nom utilisé sous l'occupation japonaise pour désigner Séoul.

46. TAkeuchi, 2013, p. 396.

47. INOUE, 1974 [1963]. 
l'époque de la guerre ${ }^{48}$, ce roman demeure particulièrement frappant en ce qu'il réunit dans une discrimination similaire trois populations très différentes, mais toutes au plus bas de l'échelle sociale : mineurs, hibakusha et burakumin.

À l'âge de quinze ans, Unan Chikao travaillait dans une mine de charbon sous la mer. Alors qu'il s'apprêtait à passer un examen afin d'entamer des études supérieures, il apprit soudain la grossesse de Shu Hōko, sa maîtresse coréenne, par ailleurs chargée de distribuer les lampes dans la mine. Assumer sa responsabilité et épouser Hōko ne signifie cependant pour lui qu'une seule chose : être condamné toute sa vie au travail de mineur.

Alors que tu pensais passer l'examen, intégrer une école supérieure et en finir avec la mine de charbon, alors que cette chance était là, juste devant toi... tu as eu peur que ta vie soit fichue s'il venait à se savoir que tu avais fait un enfant à une femme qui distribuait les lampes, s'il venait juste à se savoir que Shu Hōko était enceinte de ton enfant. Or, les choses se sont arrangées comme tu le voulais, comme tu l'espérais le plus. Shu Saiko était forte en gueule, mais elle ne savait que faire quant à l'état de sa jeune sœur. Elles étaient de plus en plus désemparées. Cependant, c'était une chance pour toi. Shu Hōko ne supportait plus d'entendre sa sœur lui faire des reproches et se lamenter tous les soirs. Alors, elle a décidé d'en finir avec son état. [...]

Lorsqu'elle est grimpée sur les pieux, elle a dû appeler ton nom, c'est sûr. Elle est tombée la tête en bas, les yeux fermés, en écoutant les oiseaux stupides piailler. Non, peut-être bien qu'elle avait les yeux ouverts, des larmes plein les yeux. Et Shu Hōko est morte. Pas seulement son enfant, mais elle-même aussi.

検定試験を受けて上級学校に入り、なんとしても炭鉱 を脱けだしたい、と考えていたそのチャンスが目先にぶ ら下がっていた時、朝鮮人の安全灯婦に子供を生ませた んじゃ、いや、朱宝子がお前の子供を妊娠したというこ

48. Ibid., p. 102. 
とが知れただけで、お前はもう永久に葬られてしまうの だからな、お前は必死だったのだ。……それでも事は、 お前が願っていた通り、そうなればよいといちばん願っ ていた通りに運んだ。強いことはいっていたが、朱宰子 は妹の体をどう始末してよいかわからなかった。そし て朱宰子は妹と一緒に二人とも追いつめられていったの だ。しかし、それがかえってお前に幸いした。姉から毎 晚のように責められ、なげかれるのに耐えかねて、朱宝 子は自分で自分の体の始末をつけようと決心したのだ。

$(…)$ 朱宝子は杭木を這い上がる時、きつとお前の名 前をよんだにちがいない。それから闇の中でバカ鳥が啼 くのをききながら、眼をつぶってまっさかさまに滑り落 ちた。いや、もしかすると眼はひらいていたかもしれな い。いっぱい涙をためながら。そして朱宝子は死んだの だ。腹の中の子供じころか、自分まで死んでしまったの だ ${ }^{49}$ 。

Devenu médecin, le protagoniste est hanté par ce souvenir. Au sein de ce couple de mineurs, Unan Chikao était doublement en position de force. La tragédie de cette jeune fille n'est autre que la reproduction du rapport colonial : sa vie pesait moins lourd que la réussite sociale de son amant.

Or, la chute de l'empire japonais ne marque en rien la fin de ce type de rapports de force. Inoue Mitsuharu évoque un sujet semblable dans une autre œuvre, «Le dépôt de pieux ${ }^{50}$ », dont l'intrigue se déroule durant l'aprèsguerre. Sakura Hiroshi, syndicaliste de la mine, change d'attitude envers sa petite amie, Murakawa Shōko, lorsqu'il apprend que le père de sa fiancée est coréen. Il n'est pas prêt à abandonner sa position toujours plus importante au sein du syndicat en épousant une fille à demi coréenne. Lâche, le syndicaliste n'a pas le courage d'avouer à son amie la raison pour laquelle il la repousse, ni de rompre complètement avec elle. Shōko, enceinte, essaie de tuer Hiroshi en lui plantant

49. Ibid., p. 224-225.

50. Inoue, 1974 [1959]. 
une paire de ciseaux dans le corps, juste avant de les retourner contre sa propre personne.

Ainsi, les rapports coloniaux entre hommes japonais et femmes coréennes n'ont pas pris fin avec la défaite. Dans cette nouvelle, Shōko raconte à son fiancé l'histoire d'un homme poursuivi par la haute police spéciale et caché dans une communauté coréenne, pendant la guerre. Ce dernier a un enfant avec une jeune fille coréenne, qui le recherchera après le conflit. Une fois retrouvé, l'homme refuse cependant de reconnaître son enfant. Le parallèle que Shōko dresse entre cet homme et son amant est frappant. Comme Ikeda Hiroshi le remarque judicieusement ${ }^{51}$, ce rapport de domination entre l'homme japonais et la femme coréenne de ce roman est précisément celui que les Japonais ont entretenu à l'égard des Coréens dans les mines de charbon. Un rapport qui ne disparaît pas avec la fin de la guerre, et perdure même après la colonisation.

Contrairement à Shu Hōko, qui n'apparaît dans aucune scène de confrontation avec Unan Chikao, Murakawa Shōko prend son destin en main en essayant de tuer son amant. Or, cet acte de désespoir n'efface pas la domination coloniale. L'écrivain continue donc son processus de dénonciation : la violence coloniale n'a non seulement pas pris fin, mais elle détermine toujours le rapport entre hommes et femmes, entre Japonais et Coréens.

\section{Le temps de la révolte}

Les mineurs coréens, qui travaillent dans des conditions bien plus difficiles que leurs collègues japonais, subissent-ils pour autant leur sort sans réagir ? L'évasion d'Insun de La Lampe à alcool et le mouvement indépendantiste organisé par le docteur Iwasa dans «La raclée coréenne » laissent supposer le contraire. Dans l'univers littéraire d' Inoue, les mineurs coréens ne sont pas simplement les victimes passives de la violence des autorités. La résistance des Coréens dans les mines est d'ailleurs un fait historique avéré, mentionné par de multiples ouvrages. Dans Tomoko, récit autobiographique intégralement consacré à la question du système

51. IKEDA, 2012, p. 418-419. 
d'entraide des mineurs, Takahashi Kiichirō 高橋揆一郎 (1928-2007) mentionne la révolte qui souleva les Coréens dès la défaite du Japon, le 15 août 1945 :

Rien de bon ne nous arrivait, et la vie devenait lentement difficile, comme si l'étau se resserrait autour de nous. Au bout du compte, alors que nous commencions à ne plus avoir de quoi nous vêtir, ni même nous nourrir, vint le fameux 15 août.

Comme partout ailleurs, des syndicats se formèrent dans la mine ; c'était comme si on nous libérait d'un cachot. La révolte des Chinois et des Coréens qui avaient été emmenés là de force et contraints de travailler dans des conditions parfaitement absurdes éclata au même moment. À Hokkaidō, 3000 Chinois et 40000 Coréens formèrent des réseaux d'entraide et se révoltèrent de façon organisée.

Les violences n'étaient pas seulement dirigées contre les Japonais. Chinois et Coréens eurent également maille à part, avec morts et blessés, et la mine se mua en zone de non-droit. Même chose du côté de chez Ryōsuke, à Kamiutashinai : les Coréens emportèrent les denrées de rationnement, et tous ceux qui avaient quelque chose à se reprocher partirent se cacher dès le début des représailles contre les cadres et les contremaîtres.

いいことなどひとつもないままに、じわじわと首を絞 められるように暮しが穹迫し、最後は衣食ともにがらが らになるうちに炭砿長屋にもようやくあの八月十五日が きたのだった。

ごこでもそうであったように、炭砿でも檻から放たれ たように続々と労働組合が結成されていった。同時に迎 えたのが強制徴用されて話にならない労働条件のもとで 酷使されていた中国人、朝鮮人の蜂起だ。

北海道では中国人三千人、朝鮮人四万人がそれぞれの 仲間たちと連携しながら組織的な暴動を起こした。 
152 Cahiers d'études japonaises $n^{\circ} 23$

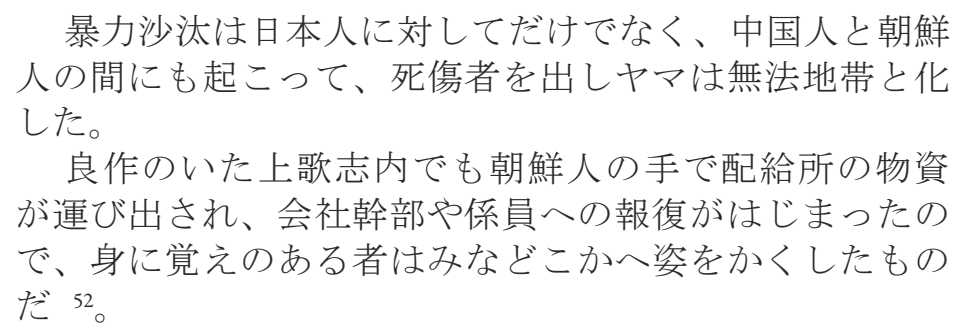

Selon cet ouvrage, la révolte des travailleurs chinois et coréens aurait ainsi commencé immédiatement après la Seconde Guerre mondiale : la fin de la guerre, bouffée d'air pur pour les peuples colonisés et contraints de travailler dans les mines, signifiait également un renversement de position entre ces travailleurs et leurs chefs. La narratrice de « La raclée coréenne », décrivant une scène qu'elle aperçoit à Tōkyō, aborde également cette question de la défaite vers la fin de la nouvelle. Croisant un camion dans lequel sont entassés des Coréens en route vers leur pays, elle voit soudain un jeune homme danser, qu'elle compare à un papillon virevoltant après avoir réussi à échapper à une tarentule ${ }^{53}$. La métaphore est significative : les Coréens qui subissaient la «trempe coréenne » ont enfin échappé à la vie empoisonnée des colonisés.

Dans La Grue imaginaire, publié en $1960^{54}$, Inoue Mitsuharu met d'autre part en scène la question des vols de denrées alimentaires commis juste après la défaite. Cette fois-ci, cependant, ce sont les Japonais qui en sont les auteurs : le protagoniste de ce roman, Nakadai Kurao, s'empare en effet de denrées militaires avec ses amis dès la fin du conflit, puisque l'État japonais, s'apprêtant dans sa folie à continuer la guerre envers et contre tout, stockait toutes sortes de denrées en importantes quantités - alors même que la population « crevait » littéralement de faim. Le titre du roman est d'ailleurs ambivalent, car s'il fait référence à un outil dédié aux grands travaux, le texte dans son entier décrit un pays en ruines. La grue est-elle l'instrument qui va servir à le reconstruire, ou le symbole de

52. TAKAHASHI, 1991, p. 160.

53. YUZURIHARA, 2012 [1949], p. 555-558.

54. INOUE, 1974 [1960]. 
l'édification illusoire d'une ère expansionniste révolue ? Autre élément important de ce portrait d'un Japon en déchéance, une scène du roman est particulièrement éloquente quant au rapport des Japonais avec les Coréens entraînés dans cette situation démente. Après avoir subi un bombardement à Tōkyō, Nakadai Kurao rentre chez sa grand-mère dans le Kyūshū et prend un bateau afin de traverser le détroit de Shimonoseki. À bord, il rencontre un groupe d'officiers stagiaires, ainsi que des Coréens fraîchement embarqués. Mais le bateau essuie un bombardement, et les passagers coréens sont pris de panique. Le capitaine ordonne alors à ses subordonnés de dégainer leur sabre afin de les faire taire. L'un des Coréens, doublement terrifié, crie soudain l'unique phrase en japonais qu'il connaisse : « aller à la mine pour l'empereur » (tennō heika no tame, tankō yuku テン) 一ヘーカノタメ、タンコーユク ${ }^{55}$, ce qui redouble la colère de l'officier. Ces Coréens, qui ont probablement été conduits de force au Japon, sont en route vers une mine de la région de Chikuhō. La situation tourne à l'absurde : les officiers stagiaires dégainent face à ces gens légitimement paniqués, puisqu'il s'agit de leur première expérience d'un bombardement. Les Coréens sont en effet totalement inoffensifs, et la réaction des officiers, disproportionnée : les sabres ne servent absolument à rien face aux bombes incendiaires. Cette scène illustre très précisément l'orgueil démesuré envers les Coréens animant un Japon impuissant face à l'armée américaine. Le protagoniste va également retrouver ce type de comportement au sein de la mine de Tojima, où il a déjà travaillé et s'apprête à travailler à nouveau. Lorsque Nakadai Kurao aperçoit les futurs mineurs sur le bateau, il se rappelle du spectacle quotidien des travailleurs coréens frappés avec une ceinture de caoutchouc pour avoir abandonné leur poste. Les lecteurs sont mis au courant, avant même l'arrivée de ce personnage à la mine, du conflit opposant les mineurs coréens et les Japonais en position de force.

L'un des épisodes principaux de La Grue imaginaire décrit précisément la révolte silencieuse des mineurs coréens qui survient dans le roman. Le début de l'affaire s'ouvre sur un dialogue bancal :

55. Ibid., p. 55. 
«C'est vrai que tu n'es pas au courant, Nakadai... Bon, faut pas trop en parler, mais il s'agit du Coréen réquisitionné, Sai. L'un de ceux qui ont été emmenés au début de l'année par bateau. Hé bien, il s'est pendu il y a une dizaine de jours. Ça, on n'y peut rien, mais comme les autres Coréens réquisitionnés se sont plaints, on a organisé des funérailles dans les règles, et c'est alors qu'on portait le corps vers le crématorium qu'il s'est passé quelque chose. »

L'ingénieur Tanita s'arrêta et reprit comme s'il hésitait.

« Bon, d'accord, je vais te le dire, sinon tu ne vas rien comprendre. Mais je te prie de ne le répéter à personne, parce qu'on m'a formellement interdit d'en parler. Quand on se dirigeait vers le crématorium,.. comment dire ? On a trouvé à l'embranchement qui va du bas du terril vers la mer une demie-feuille, qui portait l'inscription : "Coréens, soyez patients, c'est pour bientôt"...

— C'était écrit sur une feuille ? demanda le préposé Shōno.

- Oui, répondit l'ingénieur. Il paraît d'ailleurs que quatre pièces d'un sen en bronze tenaient lieu de pierres aux quatre coins de la feuille manuscrite.

- Encore ? Il y avait souvent ça, avant, fit l'assistant Iwamatsu, comme s'il était impressionné. C'était écrit "Coréens, soulevez-vous" ?

— Pas "soulevez-vous", mais "soyez patients". »

$[\ldots]$

«Pourquoi il y avait quatre pièces en bronze d'un sen ? dit le contremaître Ono.

- Probablement pour que la feuille ne s'envole pas. Mais ils auraient pu le faire avec des pierres... »

L'ingénieur Tanita se contredisait lui-même.

« C'est peut-être pour que ça se remarque davantage, fit l'assistant Iwamatsu. Je crois comprendre ce "soyez patients", mais qu'est-ce que ça veut dire, "c'est pour bientôt" ? »

「仲代君はしらなかったんだね。……をそれもあま りいってもらっては困るが、その崔という徴用鮮人のこ とだ。今年のはじめ船でつれてきたうちの一人だがね。 
これが十日ばかり前、首吊りをやったんだ。それはまあ それでいいんだが、徵用鮮人が騒いだので、一応型通り の葬式をやって火葬場にその死骸を運ぶ途中で、あるこ とがおこったんだ。……そこで谷田技師はためらうよ うに言葉をきってつづけた。

「まあ、よからう、これをいわなければ何もわからん からね。しかし硬くとめられたことだからこれから先の ことは、誰にもしゃべらんで下さいよ。……何とい うか、その火葬場にいく途中でね。ボタ山の下から海に いくあのわかれ道のところで、朝鮮人たちもう少しがま んしろ、もうすぐだ、と書いた半紙が落ちていたという のだがね。….」

「半紙にかいてあったんですね」庄野係員はきいた。

「そうです。あ、そうだ、その、そんなことが鉛筆で かいてある半紙の上に一銭銅貨が四枚、四隅に石の代わ りのようにおいてあったというんだ」谷田技師はこたえ た。

「へえ、今どきね。昔ならよくあったが、朝鮮人起ち 上れとかいてあったんですか」岩松助手は感嘆したよう に声をあげた。

「起ち上れじゃないでしょう、がまんしろじゃないで すか」小野係員はいった。

$(\cdots \cdots)$

「半紙の上に一銭銅貨を四枚おいていたというのはど ういうわけでしょうかね」小野係員はいった。

「半紙が飛ばんようにでしょう。いや、飛ばんように なら石でもできるわけだけど……谷田技師は自分で自 分の言葉を否定した。

「それは目立つようにしたんでしょう……岩松助手 がいった。「その、朝鮮人がまんしろ、というのはわか らんことはないが、もうすぐだ、というのはどういう意 味でしょうかね永年」 
Dans ce dialogue, les personnages passent à côté de l'essentiel ; ils ne comprennent pas la portée de cette affaire. Non seulement le suicide d'un travailleur coréen ne suscite-t-il aucune émotion dans l'assistance, mais il est explicitement précisé que ses funérailles ont été organisées contre le gré des Japonais, juste pour calmer les Coréens. Les questions d'importance sont totalement ignorées, que ce soit la raison de ce suicide, ou la cause du message trouvé sur le chemin du crématorium. En revanche, l'utilisation des pièces suscite davantage l'intérêt de l'assemblée. Ce passage montre clairement que si la vie d'un Coréen n'a pas de valeur pour les salariés de la mine, leur désobéissance, elle, leur est insupportable. Il fait écho à l'absurdité de l'épisode du bateau, que Nakadai se remémore en assistant à cette conversation. Après des dénonciations en chaîne extorquées sous la torture, la chasse à l'auteur de ce message aboutira in fine à un second suicide, qui précèdera de peu l'annonce de la défaite du Japon.

Si La Grue imaginaire décrit à travers des scènes grotesques l'absurdité d'un Japon impérial à la dérive, ce roman lance également un avertissement au Japon d'après-guerre, qui n'a pas su remettre en question son comportement. Même après la défaite de l'empire et l'indépendance de la Corée, Inoue Mitsuharu a continué de dénoncer l'incompréhension et le déni japonais. La mine est d'ailleurs restée pour lui un thème privilégié : dans des œuvres telles que « Le lendemain des femmes enceintes ${ }^{57}$ » ou « Le pays natal affamé $^{58} \gg$, il évoquera ainsi le destin de mineurs tombés encore plus bas dans la hiérarchie sociale une fois devenus chômeurs. Les Coréens repartis dans leur pays sont absents de ces romans ; seul Les Classes sociales ${ }^{59}$, publié en 1968, fait figure d'exception. Ce récit met précisément en scène les souffrances intactes des mineurs, que le temps n'a pas effacées. Mais ces souffrances peuvent-elles être balayées ? Le pardon est-il possible?

Été 1966, dans un bus qui relie Sasebo et Hiradoguchi. Ariie Naomichi, étudiant à Tōkyō, entend un passager, marchand ambulant de son état, raconter une étrange histoire. Près de l'ancien site charbonnier de Gigan existerait un

57. InOUE, $1964 \& 1975$ [1965], p. 199-218.

58. InOUE, 1974 [1965].

59. InOUE, 1972 [1968]. 
hameau de marutan マルタン (anciens mineurs), où un homme vit en compagnie de quelques trois cents rats. Le marchand prétend avoir vu un chien vivant jeté au milieu de ces rats, qui l'auraient immédiatement attaqué. De l'animal qui se débattait, n'est plus resté qu'un tas d'os. Les Classes sociales débute ainsi avec une histoire macabre qui ne laisse pas ses lecteurs indifférents. Le lieu en question (le hameau des marutan) et l'époque (postérieure à la fermeture de la mine) sont d'emblée annoncés. Plusieurs récits parallèles se déroulent à Gigan et Hanami, une autre ancienne ville minière à proximité, ce qui permet de souligner le délabrement de ces villes et la misère des anciens mineurs au chômage.

Le protagoniste n'imagine pas à cet instant, dans le bus, qu'il rencontrera un jour l'homme aux rats. Ariie Naomichi rentre dans son village natal dans le Kyūshū afin de percer le mystère de la disparition de son père, ancien patron de la mine de Hanami, mort dans un incendie trois ans auparavant. Certains prétendent que l'homme est entré dans son bureau en feu afin de récupérer un dossier important ; d'autres soutiennent qu'il était déjà mort lorsque le bureau a pris feu. Naomichi découvre, au fur et à mesure que le roman avance, que son père n'était pas forcément aimé par ses salariés.

Contrairement aux autres œuvres d'Inoue, ce roman ne s'étend pas spécialement sur les conditions de travail des Coréens dans la mine pendant la Seconde Guerre mondiale. Cependant, en enquêtant sur la mort de son père, l'étudiant découvre qu'un employé nommé Saikawa Haruo s'est pendu juste après l'incendie. Cet électricien coréen était-il l'assassin du patron de la mine ? Le roman ne fournit pas davantage d'informations à ce sujet, mais la découverte de cette deuxième mort conduit Ariie Naomichi à rencontrer le frère du défunt électricien, Saikawa Shun.i. Leur entretien prend une direction inattendue, et ce dernier enferme Ariie dans un débarras.

«Écoute-moibien, poursuivitl'homme d'une voix basse et noire, mais qui portait bien. Au début de 1945, Ariie Shigeyuki venait de succéder à son père à la tête de la mine de Hanami. Ton grand-père était mort d'une attaque cérébrale. À ce moment-là... Tu sais qu'il y a eu une explosion de gaz dans la fosse $\mathrm{n}^{\circ} 2$, en février 1945 ?

- Non, je ne le savais pas. 
- Tu ne sais pas que du méthane a explosé et que la taille ouest de la fosse $n^{\circ} 2$ ainsi qu'une partie de la galerie $n^{\circ} 3$ ont été anéanties ?

- Je n'en ai jamais entendu parler, répondit-il.

- Mon père était dans la galerie $\mathrm{n}^{\circ} 3$. Quand la taille ouest a explosé et que tous les mineurs qui travaillaient là sont morts, mon père, lui, était encore vivant dans la galerie $n^{\circ} 3$. On aurait pu le sauver, si on l'avait voulu. Mais Ariie Shigeyuki l'a laissé mourir sans rien faire. Non, il a fait pire encore : il savait qu' il y avait encore deux mineurs coréens vivants, mais il a fait fermer le passage entre la galerie $n^{\circ} 3$ et la galerie $n^{\circ} 2$. "Aidez-nous, laissez-nous sortir !", ontils crié, inutilement. Craignant que le feu n'atteigne la galerie $\mathrm{n}^{\circ} 2$, Ariie Shigeyuki a utilisé les hommes comme sacs de sable. Pour ton père, il n'était pas concevable de sacrifier la galerie $\mathrm{n}^{\circ} 2$ afin de sauver un ou deux minables mineurs coréens. Mais les morts ? Et la famille des morts ? S'ils étaient morts immédiatement à cause d'une explosion de gaz, on aurait pu l'accepter, et il y aurait eu de l'espoir. Mais mon père était vivant. Ils avaient suffisamment de temps pour le sauver. Et quand bien même, s'ils avaient évité de fermer le passage entre la galerie $n^{\circ} 2$ et la galerie $n^{\circ} 3$ aussi rapidement sans tenir compte des survivants, mon père aurait pu sortir, même en rampant... »

Comme l'homme s'arrêtait, Ariie Naomichi dit :

« Laissez-moi sortir. Je vous écouterai à l'extérieur.

- Une personne qui était dans la galerie ${ }^{\circ} 2$ a entendu la voix de mon père. "Aidez-nous !", a-t-il dit deux ou trois fois, d'une voix rauque. Elle l'a ensuite entendu crier : "vous allez nous faire mourir brûlés vifs !” »

\footnotetext{
「おれのいうことをきけ」男は低いがよく通る黒々 とした声でつづけた。「昭和二十年のはじめ、有家重行 は波並炭鉱を受け継いで責任者になったばかりだった。 お前のじいさんが卒中で倒れたからな。その時……お前
} 
は昭和二十年の二月に起きた二坑のガス爆発を知っとる か」

「知らん」彼はいった。

「メタンが爆発して二坑の西払と三号の堀進の一部が 全滅したことを、お前はきいてもおらんのか」

「きいてない」彼は答えた。

「三号堀進におれの父親はいたんだ。西払が爆発し て、そこに働いとった坑夫が全部死んでしもうた時、お れの父親は二号堀進でまだ生きていた。助けようとすれ ば何としても助けられた。それを有家重行は夕す夕す見 殺しにした。いや、見殺しにするよりもっとわるい。三 号にはまだ朝鮮人の坑夫が二人生きとることを確認して いながら、三号と二号の間を遮断してしもうたんだ。助 けてくれ、ここからだしてくれといくらおらんでもどう にもならん。二号に引火することを恐れて、有家重行は 行きとる人間を砂囊代わりにした。お前の親父にしてみ れば、一匹か二匹の朝鮮人坑夫を助けるために二号堀進 を犠牲にすることはできんといいたいのだろうが、死ん だ者はどうなる。死んだ者の家族はどうなる。それもガ ス爆発の即死なら、まだ考えようもあるし、残った者は 救われもする。しかしおれの親父は生きていたんだ。助 ける時間は充分あった。助けなくてもいい、二号と三号 の間を早々と、行きとる人間のいることを無視して遮断 さえしなければ、おれの父親は匍ってでも逃げ出すこと ができたんだ。…..

男の言葉が途切れたので、有家直道は「だしてくれ」 といった。「話は外できく」

「二号堀進にいた者が、父の声をきいとる。助けて くれと、父はかすれた声で二度か三度たのんだ。それか ら、おれ達を焼き殺す気か、とおらぶのがきこえたそう だ 60

60. Ibid., p. 173-174. 
160 Cahiers d'études japonaises n²3

Voyant que son récit ne suscite aucune émotion chez l'étudiant, Saikawa Shun.i introduit les rats affamés dans le débarras. L'homme qui élève ces bêtes, en effet, n'est autre que le frère du défunt électricien. Ce personnage de Coréen n'est pas fortuit : la mort des Coréens, qu'il compare à celle d'animaux, n'a aucune valeur face aux profits de la mine de charbon. Les dates des deux décès sont par ailleurs symboliques : le premier remonte à février 1945, juste avant la défaite du Japon et l'indépendance de la Corée ; le second à 1963, dix-huit ans après la fin de la guerre. Le père a donc raté l'indépendance et le possible retour en Corée à quelques mois près ; le frère, Haruo, est certes mort près de deux décennies après la fin de la période coloniale, mais dans des circonstances mystérieuses, puisque plane autour de sa disparition le soupçon de tortures policières, ce qui ne manque pas de rappeler les pratiques évoquées dans La Grue imaginaire. Le doute est d'autant plus grand que sa mort est rapportée dans le dossier de police comme une simple pendaison, sans qu'aucune mention ne soit faite du lieu de sa mort - la cellule. Ni les causes de la mort du père de Ariie Naomichi, ni les circonstances du « suicide » de Saikawa Haruo ne seront d'ailleurs complètement élucidées dans le roman : tout comme le coup de grisou qu'Ariie ignore, cette mine renferme des secrets. Le récit entre les mains de la police fait certes office de « version officielle » de l'incendie, mais sert en réalité à détourner de la vérité. Devant cet « abus d'oubli » orchestré (car « on peut toujours raconter autrement, en supprimant, en déplaçant les accents d'importance, en reconfigurant différemment les protagonistes de l'action ${ }^{61} \gg$ ), le frère du défunt ne peut opter que pour la vengeance. La chose est tout à fait intéressante du point de vue littéraire : pour conduire à la vérité, la fiction reconstruit en somme un autre récit à partir des mêmes éléments, un récit opposable au second récit fictif, celui des versions officielles, qui sert précisément à écarter les protagonistes de la vérité. Or, cette vengeance du frère n'est autre que celle des mineurs coréens ayant travaillé dans des conditions atroces et perdu leur vie durant la période coloniale. Lorsqu'il existe une réticence à reconnaître les faits historiques chez

61. RiCCEUR, 2000, p. 579-580. 
certains historiens, et que la réparation de l'État se montre difficile à obtenir ${ }^{62}$, la fiction permet donc d'envisager d'autres stratagèmes.

Inoue Mitsuharu s'inscrit par conséquent dans la lignée de ses prédécesseurs, ces écrivains militants de la littérature engagée qui souhaitaient dénoncer dans toute leur ampleur les crimes de la colonisation et la barbarie des traitements infligés aux mineurs coréens. Son œuvre revêt d'ailleurs à ce titre un grand intérêt documentaire. Mais la réduire à ce seul aspect ne serait pas lui rendre justice : comme en témoigne de façon si spectaculaire Les Classes sociales, Inoue ne se contente pas de mettre en place un dispositif «vraisemblable » pour appuyer son récit et défendre une cause, ce que l'on pourrait finalement reprocher à la littérature engagée. Il élabore de véritables intrigues, et construit de solides fictions, annonçant par là un nouveau genre de littérature dans laquelle la mine allait trouver sa place : le roman policier.

\section{Le tournant du roman policier}

Shimada Sōji et Hahakigi Hōsei sont deux autres auteurs « miniers » à avoir écrit sur le thème de la vengeance, quoiqu'ils se distinguent clairement d'un héritier de la littérature prolétarienne tel qu'Inoue Mitsuharu, de par leur naissance postérieure à la période d'après-guerre comme leur spécialisation dans le polar. Aussi sera-t-il pertinent d'examiner comment ce profil d'écrivain a pu choisir d'articuler dans ses œuvres les trois éléments de l'équation étudiée dans ces pages : houillère, colonisation et mémoire. Nous nous intéresserons ici plus particulièrement à deux romans : Une Idée originale remue le ciel ${ }^{63}$, de Shimada Sōji, paru en 1989, et Trois Fois le détroit ${ }^{64}$, de Hahakigi Hōsei, publié en 1992.

Que ces romans relèvent tous deux du genre « policier » (suiri shōsetsu 推理 小説) n'est probablement pas le fruit du hasard. Le dictionnaire japonais Köjien définit le suiri shōsetsu comme suit : « roman dont le sujet principal concerne
62. YAMADA et al., 2005, p. 32-38.
63. Shimada, 2002 [1989].
64. HaHAKigi, 2000 [1992]. 
162 Cahiers d'études japonaises n²3

l'élucidation d'un secret autour d'un meurtre, et qui concentre son intérêt sur la déduction du mobile et du modus operandi de ce crime ${ }^{65}$. $\gg$ D'autre part, le milieu des années 1980 voit le passé de la Corée du Sud et du Japon commencer à ressurgir dans les débats médiatiques. Selon une étude de Kimura Kan ${ }^{66}$, spécialiste des relations entre ces deux pays, on constate entre 1984 et 1985 une augmentation du nombre d'articles parus dans le journal Asabi autour de la question de la responsabilité du Japon pendant la Seconde Guerre mondiale ${ }^{67}$. Lorsque ce sujet a refait surface dans les médias, Shimada comme Hahakigi ont probablement trouvé dans les mines de l'empire japonais le cadre idéal de leurs romans policiers.

Une Idée originale remue le ciel commence de manière quelque peu rocambolesque. En 1989, lors de l'introduction au Japon de la taxe sur la valeur ajoutée, se produit un meurtre que les médias appellent «l'affaire TVA ». Un vieillard gâteux aurait en effet tué d'un coup de couteau la patronne d'un magasin d'alimentation, fâché qu'elle ait exigé qu'il paye la toute nouvelle TVA, d'un montant dérisoire de douze yens. L'affaire prend cependant une tournure inattendue lorsque le policier chargé de l'enquête, Yoshiki Takeshi, au demeurant guère convaincu par le mobile de cet assassinat, découvre que le vieillard avait l'esprit clair au moment des faits. Sa certitude se confirme : cet homme n'a pas commis le meurtre à cause des douze yens de TVA. Le criminel est un Coréen du nom de Ro Taiei, emmené de force au Japon avec son jeune frère Taimei pendant la Guerre du Pacifique. Après avoir travaillé sur un chantier à Karafuto, les deux frères avaient atterri dans la terrible mine de charbon de Kawakami, où se pratiquait « la raclée coréenne ». La majorité des Coréens furent abandonnés sur l'île après la défaite du Japon ; les frères Ro, eux, réussirent à quitter Karafuto pour gagner Hokkaidō, où ils travaillèrent dans un cirque. Taimei tomba alors amoureux de Sakurai Keiko, la vedette de la troupe, qui utilisa cependant les frères afin de quitter le cirque pour retrouver son amant, un chef yakuza avec qui elle souhaitait vivre à Tōkyō. Au cours de cette cavale, Taimei fut tué par un voyou

\footnotetext{
65. Köjien daisanpan, 1990, p. 1272.

66. Kimura, 2007, p. 64.

67. Ibid., p. 67.
} 
chargé d'escorter Keiko auprès de son chef : pour les deux frères, le rêve de rentrer en Corée se brisa définitivement à cet instant. Ro Taiei, qui cherchait depuis trentedeux ans à venger la mort de son cadet, avait enfin découvert Sakurai Keiko en la personne de la patronne de boutique. Impressionné par cette affaire, le policier Yoshiki Takeshi y voit un résumé de l'ère Shōwa ${ }^{68}$.

Yoshiki raccroche le téléphone, mais se demande si cette affaire est réellement résolue. Ro est encore au Japon ; sa femme, en Corée du Sud. À Sakhaline, il reste encore un peu plus de quarante mille Coréens.

Même s'il n'y pensait jamais d'ordinaire, il est évident que les crimes de guerre, les crimes qu'ont commis les Japonais il y a plus de quarante ans, ne sont toujours pas réglés. Évidemment, il est bien plus confortable de les faire passer pour des crimes de guerre...

受話器を置き、しかし、本当に事件は解決したのだ ろうかと考える。韓国に妻がいる呂は、いまだ日本にい る。サハリンには、まだ四万人以上の朝鮮人が残ってい る。

普段は考えることもなかったが、四十数年前の戦争と 日本人の罪が、この国にまだ処理されずに残っている。 これを戦争の罪と言ってしまえれば楽なのだが一 69

Par le biais du personnage du Coréen qui se venge, l'écrivain illustre les noirceurs de l'ère qui vient de se terminer. Cette vengeance ne vient pas uniquement sanctionner la mort du frère, mais toutes les souffrances qu'il a dû plus généralement endurer : le déplacement forcé, le travail à la mine dans des conditions inhumaines, l'abandon à Karafuto par le gouvernement japonais, le retour impossible au pays. Elle devient celle de tous les Coréens ayant souffert du colonialisme, et le simple roman policier qu'était Une Idée originale remue le ciel bascule dans le roman engagé.

68. Shimada, 2002, p. 439.

69. Ibid., p. 445. 


\section{CIPANGO}

164 Cahiers d'études japonaises $n^{\circ} 23$

Trois fois le détroit met également en scène la mine et la vengeance, mais fait le choix d'un protagoniste coréen, à la différence des autres écrivains japonais précités. Tout le roman est ainsi raconté par un je-narrateur, Ha Sigŭn. Le titre désigne les traversées du détroit de Daikan (Tsushima) qu'il a effectuées : une première fois à l'âge de dix-sept ans, en 1943, alors qu'on l'emmenait de force pour travailler dans une mine du Chikuhō, une deuxième fois en 1945, pour vivre en Corée avec une femme japonaise, et la troisième fois dans les années 1990, afin de venger ses compagnons d'infortune de la mine. Ha Sigŭn fut originellement embarqué pour le Japon à la place de son père, trop malade pour y travailler. Une fois arrivé sur l'île de Kyūshū, dans la ville de N., un labeur extrêmement dangereux l'attendait. Les Coréens de la mine étaient mal nourris, menacés de punitions corporelles à la moindre occasion, avec des sanctions d'une extrême violence en cas de fuite. Plusieurs camarades de Ha Sigŭn y perdront d'ailleurs la vie. Malgré les risques auxquels il s'exposait en s'évadant, le jeune homme parvint à s'échapper de la mine au bout de quatorze mois de travail, pour se réfugier dans un hameau Arirang ${ }^{70}$ précédemment visité avec ses camarades, lors d'une journée de congé.

Ha Sigŭn travailla par la suite dans un port, comme docker, et rencontra une femme japonaise, Chizu, avec laquelle il partit en Corée après la défaite du Japon. Mais ni la famille de Ha Sigŭn, ni les villageois n'autorisèrent cette union : après avoir donné naissance à un garçon, Chizu fut contrainte de repartir au Japon. Remarié et père de trois fils, Ha Sigŭn retrouvera son fils aîné au Japon lors de sa troisième traversée du détroit. Il laisse à ses enfants des mémoires intitulés Trois Fois le détroit, comme si le roman entier était un testament dédié à ses fils. L'objectif de cette dernière traversée, toutefois, n'est pas seulement de retrouver ce fils qu'il n'a connu qu'en bas âge, mais aussi de contrecarrer le projet proposé par Yamamoto Sanji, un candidat à la mairie de N. Cet homme, dont la promesse électorale vise à faire disparaître le terril de N., témoin du passé minier de la ville, n'est autre que le terrible contremaître qui causa jadis la mort de plusieurs de ses

70. Les 《hameaux Arirang 》 (Ariran buraku アリラン部落) étaient des hameaux habités par des Coréens ; il en existait plusieurs dans les vallées à proximité des mines de charbon. IKEDA, 2012, p. 218-219. 
compagnons. Ce projet, qui entraînerait de fait la disparition de leurs tombeaux au pied du terril, est de surcroît partagé par le Coréen Kang Wǒnpŏm, patron d'une entreprise de construction aujourd'hui naturalisé japonais, qui fut par le passé l'assistant du contremaître en chef et l'exécutant de ses pires bassesses à l'encontre des mineurs coréens.

L'expression « ne pas revenir sur ce qui a été fait » existe également en coréen, mais autant une victime peut se permettre de l'utiliser, autant un agresseur ne devrait pas le faire.

Quand j'ai entendu parler du projet de Yamamoto Sanji en faveur de la démolition du terril, le comportement du Japon et le visage de cet homme se sont soudain superposés dans mon esprit. Tous deux partagent la même impudence vis-à-vis de l'Histoire. Or, nous ne pouvons rien apprendre de l'avenir. Ce qui nous permet d'apprendre ne se trouve que dans le passé. Plus nous considérons l'Histoire de manière critique, et plus celle-ci étincèle à nos yeux. Rien ne se dégage d'une Histoire que nous aurions embellie ou falsifiée à notre guise, sinon une éphémère cohérence. L'illusion, si agréable soit-elle, ne dure jamais bien longtemps, et nous finissons un jour ou l'autre par recevoir la monnaie de notre pièce.

〈水に流す〉という表現は朝鮮語にもあるが、少なく ともこれは害を被った側が発する言葉で、加害者は口に すべきではない。

ボタ山を撤去するという山本三次の計画を聞いたと き、私の頭のなかでこの国のありかたと彼の姿が二重写 しになった。双方に共通しているのは、歴史に対する厚 顔さだ。私たちは未来から学ぶことはできない。学ぶ材 料は過去の歴史のなかにしかない。歴史は、批判的に眺 めれば眺めるほじ、輝きを増す。自分に都合のよいよう に、粉飾したり改変を加えた歴史からは、束の間のつじ つま合わせしか生まれて来ない。たとえそれがいかに心 
166 Cahiers d'études japonaises n²3

$$
\begin{aligned}
& \text { 地良いものであっても、長続きはせず、いつかしっぺ返 } \\
& \text { しが訪れるのだ71。 }
\end{aligned}
$$

Faute d'une justice qui reconnaîtrait les crimes de la colonisation, Ha Sigŭn est obligé de se transformer lui-même en justicier, tout comme Saikawa Shun.i. Sa vengeance se dirige à la fois contre Yamamoto Sanji et Kang Wŏnpŏm : du premier, il dévoilera le passé de bourreau pendant la campagne électorale et réussira à faire péricliter le projet, avant de se déguiser en homme d'affaire intéressé par l'exploitation du terril pour faire revenir le second sur le lieu de ses crimes, et l'y assassiner. Ce double projet de meurtre et de suicide est annoncé dans une lettre destinée à son fils, qu'il rédige peu avant le rendez-vous fatidique.

L'analogie entre la disparition du terril et l'oubli de l'Histoire est lourde de sens. Comme ce fut déjà le cas après l'accident de la mine et la mort suspecte de Saikawa Haruo, l'oubli est organisé, « motivé par une obscure volonté de ne pas s'informer, de ne pas enquêter sur le mal commis par l'environnement du citoyen, bref, par un vouloir-ne-pas-savoir ${ }^{72}$. $\gg$ La vengeance de Ha Sigŭn vise certes à réparer la mort de ses compagnons d'infortune, mais se dirige également contre cet abus d'oubli institutionnalisé.

Rien n'est plus approprié qu'une mine de charbon pour réfléchir à l'histoire moderne du Japon. Tout y est résumé. La technologie moderne, le capital, le droit, les traditions et les coutumes des travailleurs, on y retrouve absolument tout.

日本の近代を考えるのに、炭鉱ほど好都合なものはあ りません。そこにはすべてが集約されています。近代技 術も資本も、労働者の権利も伝統も因習も、何もかもが 圧縮されているのです73。

71. Hahakigi, 2000 [1992], p. 56-57.

72. Ricceur, 2000, p. 580.

73. HahaKigi, 2000 [1992], p. 377. 
Comme le dit le fils de Ha Sigŭn à son père, la mine est un concentré d'Histoire $\mathrm{du} \mathrm{Xx}^{\mathrm{e}}$ siècle. Elle a accompagné la Seconde Guerre mondiale et l'ambition démesurée du Japon impérial au détriment de la vie des mineurs, elle symbolise le crime gouvernemental d'avoir obligé les Coréens à quitter leur pays pour travailler dans des conditions inhumaines. Et c'est précisément parce que la houillère incarne cette période noire de l'histoire du Japon que Shimada et Hahakigi ont tous deux choisi de l'intégrer à leurs romans. Lorsque la responsabilité du Japon a commencé à être remise en cause aux alentours des années 1990, ces deux écrivains de la génération d'après-guerre ont cherché à affronter la période coloniale et à la dépasser. Tandis que le gouvernement japonais peinait à reconnaître ses exactions et à présenter ses excuses, les écrivains, eux, tentaient d'œuvrer à la réconciliation entre les deux peuples à travers l'écriture romanesque. Il ne s'agissait plus seulement de témoigner de l'histoire du travail forcé et de la souffrance des mineurs coréens (aspects déjà abordés, on l'a vu, par des auteurs japonais comme Yuzurihara Masako ou Īo Kenshi), mais bien de continuer le travail fictionnel amorcé par Inoue Mitsuharu.

Peut-être faudrait-il tout de même s'interroger sur le caractère paradoxal de ces vengeances symboliques. Les écrivains utilisent certes la force de la fiction, fidèles à la définition de Jacques Derrida « la littérature comme "droit de tout dire publiquement ${ }^{74 "} \gg$. S'ils offrent à leurs personnages l'occasion de se venger individuellement, le cadre particulier qu'ils choisissent pour ce faire pourra néanmoins laisser perplexe. Le roman policier est en effet le lieu privilégié de la vengeance personnelle, elle en est même un topos. Parler de la colonisation dans ce cadre précis, appartenant en outre à la littérature dite « commerciale », expose de fait l'écrivain au risque de banaliser le problème avant même qu'il n'ait été officiellement reconnu. Ces œuvres et leur contexte d'écriture sont néanmoins porteurs d'une force nouvelle : ils ont le mérite de faire sortir la question de la colonisation du seul cadre du roman militant (qui souvent, prêche uniquement des « convertis »), pour la remettre entre les mains du plus grand nombre.

74. Derrida, 2001, p. 17. 
La littérature de la mine, particulièrement âpre et austère, est concrètement très réduite en nombre. Ce constat est d'autant plus valable en ce qui concerne la littérature minière sur les travailleurs coréens, qui pour cette seule raison, mérite d'être lue, sa force documentaire étant demeurée intacte. Dans un contexte où les crimes commis par le Japon restent encore méconnus des citoyens japonais et sont souvent niés par les politiques, ces récits témoignent non seulement de l'horreur vécue par ces hommes et ces femmes dont les droits les plus élémentaires furent bafoués, mais de leur impossibilité même à dire la barbarie après l'avoir subie, ce qui contribue à l'alimenter a posteriori. Ce que cette littérature donne à connaître au fil des particularités de son histoire est irremplaçable, mais il serait injuste de la cantonner à ce rôle. Si son incursion récente dans le domaine du roman policier paraîtra contestable à l'égard de la potentielle atténuation de réalité qui pourrait en résulter, son évolution vers une fictionalisation accrue est précisément digne d'intérêt en ce qu'elle pose les questions fondamentales rencontrées par la littérature lorsqu'elle se mesure à l'atroce : que peut-on dire ? Comment le dire ?

\section{Bibliographie indicative}

Bouju Emmanuel, 2006, La Transcription de l'histoire. Essai sur le roman européen de la fin du $X X^{e}$ siècle édition critique établie par Gérard Namer, Presses universitaires de Rennes, Rennes, 209 p.

Derrida Jacques, 2001, L’Université sans condition, Galilée, Paris, 78 p.

HaHAKIgI Hōsei 帚木蓬生, 2000 [1992], Mitabi no kaikyō 三たびの海峡 [Trois fois le détroit], Shinchō bunko 新潮文庫, Tōkyō, 465 p.

Halbwachs Maurice, 2005 [1950], La Mémoire collective, édition critique établie par Gérard Namer, Albin Michel, Paris.

Hasнiмото Eikichi 橋本英吉, 1927, 《Yome-jitaku 》嫁支度 [Les préparatifs de mariage], in Bungei sensen 文藝戦線 [Le front littéraire]. 
Наsнiмото Eikichi 橋本英吉, 1930 [1927], 《Yome-jitaku 》嫁支度 [Les préparatifs de mariage], in Tankōo 炭坑, Tenjinsha 天人社, Tōkyō.

Наsнiмото Eikichi 橋本英吉, 1939, Kōdō 坑道 [Les galeries de la mine], Shun.yōdō shoten 春陽堂書店, Tōkyō.

Hasнimoto Eikichi 橋本英吉, 1946 [1928], « Hitsugi to akahata 》棺と赤 旗, in Zen.ei 前衛 [Avant-garde], Shinkō shuppansha 新興出版社, Tōkyō.

Hasнiмото Eikichi 橋本英吉, 1988 [1927], 《Yome-jitaku » 嫁支度 [Les préparatifs de mariage], in Nihon puroretaria zenshū 32 Hashimoto Eikichi Takakura Teru-shū 日本プロレタリア全集 32 橋本英吉、タ カクラ・テル集 [Anthologie de la littérature prolétarienne, vol. 32, Hashimoto Eikichi et Takakura Teru], Shin-Nihon shuppan 新日本出版, Tōkyō.

Honjō Mutsuo 本庄睦男, 1987, « Kajō naru kyōdaitachi », in Nihon puroretaria zenshū 31 Honjō Mutsuo, Suzuki Kiyoshi-shū 日本プロレタリア全集 31 本庄睦男、鈴木清集, Shin-Nihon shuppan 新日本出版, Tōkyō.

IKEDA Hiroshi 池田浩士, 2012, Sekitan no bungakushi 石炭の文学史 [Histoire de la littérature du charbon], Impact shuppankaiインパクト出版会, Tōkyō, $546 \mathrm{p}$.

Inoue Areno 井上荒野, 2013 [2008], Iya na kanji: chichi, Inoue Mitsuharu いやな感じ一父・井上光晴 [Une sensation affreuse : mon père, Inoue Mitsuharu], Kōdansha 講談社, Tōkyō.

INoue Mitsuharu 井上光晴, 1956, « Nagagutsu-tō »長靴島in Shin-Nihon Bungaku 新日本文学.

INOUE Mitsuharu 井上光晴, 1961, Ueru kokyō 飢える故郷 [Le pays natal affamé], Miraisha 未來社, Tōkyō. 


\section{CIPANGO}

170 Cahiers d'études japonaises $n^{\circ} 23$

InOuE Mitsuharu 井上光晴, 1964, «Ninputachi no asu 》妊婦たちの明日 [Le lendemain des femmes enceintes] in Sekai 世界.

Inoue Mitsuharu 井上光晴, 1972 [1968], Kaikyū 階級 [Les classes sociales], Kōdansha bunko 講談社文庫, Tōkyō, 257 p.

Inoue Mitsuharu 井上光晴, 1974 [1959], 《Kōboku okiba » 杭木置場 [Le dépôt de pieux], in Inoue Mitsuharu sakubin-shū, vol. 2 井上光晴作品集 2 [CEuvres d'Inoue Mitsuharu, vol. 2], Keisō shobō 勁草書房, Tōkyō, pp. 95-115.

InOuE Mitsuharu 井上光晴, 1974 [1960], Kyokō no kurēn 虚構のクレーン [La grue imaginaire], Shinchō bunko 新潮文庫, Tōkyō, 301 p.

InOue Mitsuharu 井上光晴, 1974 [1963], Chi no mure 地の群れ [La foule sur la terre], Shinchō bunko 新潮文庫, Tōkyō, 208 p.

INOUE Mitsuharu 井上光晴, 1974 [1965], «Ueru kokyō » 飢える故郷 [Le pays natal affamé], in Inoue Mitsuharu sakubin-shū Dainikan 井上光晴作品 集＼cjkstart第二巻, Keisō shobō 勁草書房, Tōkyō, pp. 191-224.

InOue Mitsuharu 井上光晴, 1975 [1965], Inoue Mitsuharu sakuhin-shū, vol. 3 井上光晴作品集 第三巻 [OEuvres d'Inoue Mitsuharu, vol. 3], Keisō shobō 勁草書房, Tōkyō.

Inoue Mitsuharu 井上光晴, 1979 [1965], 《 Nagagutsu-tō » 長靴島 [L'île de Nagagutsu], in Inoue Mitsubaru sakubin-shū, vol. 1 井上光晴作品 集 1 [CEuvres d'Inoue Mitsuharu, vol. 1], Keisō shobō 勁草書房, Tōkyō, pp. 145-179.

Īo Kenshi 飯尾憲士, 1974, 《Ch'oe Ǔlsun no jōshinsho » 崔乙順の上申書 [Le rapport de Ch'oe Ǔlsun] in Ryūdō 流動. 
Īo Kenshi 飯尾憲士, 2006 [1974], « Ch'oe Ǔlsun no jōshinsho » 崔乙順の 上申書 [Le rapport de Ch'oe Ǔlsun], in “Zainichi” bungaku zenshü, vol. 16, Sakubin-shū II, 〈在日〉文学全集 16 作品集 II [Anthologie de la littérature zainichi, vol. 16, OEuvres II], Bensei shuppan 勉誠出版, Tōkyō, pp. 349-365.

Īo Kenshi 飯尾憲士, 2001 [1980], 《Umi no mukō no chi »海の向こうの 血, in Souru no ihai ソウルの位牌, Shūeisha e-bunko 集英社文庫, Tōkyō.

KATŌ Shūson 加藤楸邨, 1998, Bashō zenku (chū) 芭蕉全句 中 [CEuvres complètes de Bashō], vol. 2, Chikuma Gakugei Bunko ちくま学芸文庫, Tōkyō.

KIM Hakyŏng 金鶴泳, 1973, Arukōru ranpu あるこーるらんぷ [La lampe à alcool], Kawade shobō shinsha, Tōkyō.

KIM Hakyŏng 金鶴泳, 2006 [1973], « Arukōru ranpu »あるこーるらんぷ [La lampe à alcool], in "Zainichi” bungaku zenshu, vol. 6, Kim Hak-kyeong 〈在日〉文学全集 6 金鶴泳 [Anthologie de la littérature zainichi, vol. 6 : Kim Hakyŏng], Bensei shuppan 勉誠出版, Tōkyō, pp. 175-227.

KimURA Kan 木村幹, 2007, « Nikkan kankei ni okeru “rekishi no saihakken” ni kan suru ichikōsatsu 》日韓関係における「歴史の再発見」に関する 一考察 [Une réflexion sur la 《 redécouverte de l'histoire » dans les relations entre Japon et Corée du Sud] in Kokusai kyōryoku ronshū, daijūgokan, daiichigō 国際協力論集 第15巻第1号 [Revue d'études sur la coopération internationale], $\mathrm{n}^{\circ} 1$, vol. 15 .

Kobayashi Takiji 小林多喜二, 2009, Le Bateau-usine [Kani kōsen 蟹工船], trad. Lesigne-Audoly Évelyne, Éditions Yago, Paris, 137 p.

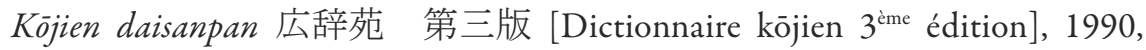
Iwanami shoten 岩波書店, Tōkyō. 
CIPANGO

172 Cahiers d'études japonaises $n^{\circ} 23$

Mryoshi Jūrō 三好十郎, 1931, Tanjin 炭塵 [La poussière de charbon], Chūō kōron-sha 中央公論社, Tōkyō.

Ricceur Paul, 2000, La Mémoire, l'histoire, l'oubli, Éditions du Seuil, Paris, $675 \mathrm{p}$.

Sebald Winfried Georg, 2001, Les Émigrants. Quatre récits illustrés édition critique établie par Gérard Namer, trad. Charbonneau Patrick, Actes Sud, Arles, 288 p.

Shimada Sōji 島田荘司, 2002, Kisō, Ten o ugokasu 奇想、天を動か寸 [Une idée originale remue le ciel], Kōbunsha bunko 光文社文庫, Tōkyō, 451 p.

TAKAHASHI Kiichirō 高橋揆一郎, 1991, Tomoko 友子, Kawade shobō shinsha 河出書房新社, Tōkyō.

Takeuchi Yasuto 竹内康人, 2013, Chōsa, Chōsenjin kyōsei rōdō 1, Tankō-hen 調査・朝鮮人強制労働 1 炭鉱編 [Le travail forcé des Coréens, ${ }^{\circ} 1$ : les mines de charbon], Shakai hyōron-sha 社会評論社, Tōkyō, 354 p.

Tonomura Masaru 外村大, 2004, Zainichi chōsenjin shakai no rekishiteki kenkyū 在日朝鮮人社会の歴史的研究 [Une étude historique de la société coréenne au Japon], Ryokuin shobō 緑蔭書房, Tōkyō, 504 p.

UENO Eishin 上野英信, 1971 [1967], Chi no soko no waraibanashi 地の底の 笑い話 [Les histoires drôles du fond de la terre], Iwanami shoten 岩波書店, Tōkyō.

YAMAda Shōji 山田昭次, Koshō Tadashi 古庄正 \& Higuchi Yūichi 樋口 雄一, 2005, Chōsenjin senji rōdō dōin 朝鮮人戦時労働動員 [Une étude historique de la société coréenne au Japon], Iwanami shoten 岩波書店, Tōkyō, 280 p. 
YI Hoesŏng 李恢成, 1970, «Kayako no tame ni » 伽耶子のために [Pour Kayako] in Shinchō 新潮, vol. 4.

YI Hoesŏng 李恢成, 1971, « Kinuta o utsu onna » 砧をうつ女 [La femme qui bat le linge] in Kikan geijutsu 季刊藝術, $\mathrm{n}^{\circ} 18$.

Yi Hoesŏng 李恢成, 2006 [1970], « Kayako no tame ni »伽耶子のために [Pour Kayako], in “Zainichi” bungaku zenshū, vol. 4, Yi Hoesŏng 〈在日〉文 学全集 4 李恢成 [Anthologie de la littérature zainichi, vol. 4 : Yi Hoesŏng], Bensei shuppan 勉誠出版, Tōkyō, pp. 97-241.

YI Hoesŏng 李恢成, 2006 [1971], 《Kinuta o utsu onna » 砧をうつ女 [La femme qui bat le linge], in "Zainichi" bungaku zenshū, vol. 4, Yi Hoesŏng 〈在日〉文学全集 4 李恢成 [Anthologie de la littérature zainichi, vol. 4 : Yi Hoesŏng], Bensei shuppan 勉誠出版, Tōkyō, pp. 243-266.

YUzURIHARA Masako 譲原昌子, 1949, 《Chōsen-yaki » 朝鮮ヤキ [La raclée coréenne] in Shin-Nibon Bungaku 新日本文学.

YUZuRIHARA Masako 譲原昌子, 2012 [1949], 《Chōsen-yaki » 朝鮮ヤキ [La raclée coréenne], in Sensō bungaku, Teikoku nippon to Chōsen, Karafuto 戦争文学 帝国日本と朝鮮・樺太 [La littérature de guerre. Le Japon impérialiste et la Corée / Karafuto], Shūeisha 集英社, Tōkyō, p. 696.

Résumé : les mines de charbon du Japon des années 1939 à 1945 comptaient de nombreux mineurs coréens, souvent arrachés de force à leur patrie et victimes de discriminations. Leur présence marque une page sombre de l'histoire du Japon. Cet épisode symptomatique de la période coloniale est visité et revisité par la littérature de langue japonaise aussi bien par des écrivains coréens que japonais. Cependant, le regard porté sur les mineurs coréens diffère sensiblement selon les origines des écrivains ainsi que leurs périodes d'écriture respectives. Ce travail 
montre que ce sujet reste tabou chez les écrivains coréens dont la communauté est pourtant directement concernée par cette mémoire. Les écrivains japonais, eux, prennent alors le relais en abordant plus frontalement la présence des mineurs coréens ainsi que le sort qui leur était dévolu. Cette intervention d'écrivains japonais est marquée également par une évolution des récits de témoignage vers des récits extrêmement romancés.

Mots-clés : littérature "zainichi”, mine de charbon, Yi Hoesŏng, Kim Hakyŏng, Yuzurihara Masako, Īo Kenshi, Inoue Mitsuharu, Shimada Sōji, Hahakigi Hōsei

Abstract: Japanese coal-mines between 1939 and 1945 counted numerous Korean miners, often torn away from their homeland and victims of various forms of discrimination. The presence of those protagonists bears witness to a dark page of Japanese history. This episode, quite symptomatic of the colonial period, is treated repeatedly in Japanese-language literature, both by Korean and Japanese writers. However, the outlook on these Korean miners changes significantly according to the origin of the authors and the respective periods in which they were writing. This article shows that the topic remains taboo among Korean writers, whose community is nonetheless concerned by this memory. As for the Japanese writers, they take over and deal very squarely with the presence of Korean miners, as well as with the destiny the latter were allotted. This contribution by Japanese writers is also characterized by a shift of the testimonies towards quite fictionalized narratives.

Keywords: Zainichi writing, coal mine, Yi Hoesöng, Kim Hakyŏng, Yuzurihara Masako, Io Kenshi, Inoue Mitsubaru, Shimada Sōji, Hahakigi Hōsei

キーワード：在日朝鮮人文学、炭鉱、李恢成、金鶴泳、譲原昌 子、飯尾憲士、井上光晴、島田荘司、帚木蓬生 